\title{
An exploration of debris types and their influence on wear rates in fretting
}

\author{
Luke Blades $^{\mathrm{a}, \mathrm{b}}$, David Hills ${ }^{\mathrm{b}}$, David Nowell ${ }^{\mathrm{b}, \mathrm{c}}$, Ken E Evans ${ }^{\mathrm{a}}$, Chris Smith $^{\mathrm{a}}$ \\ ${ }^{a}$ College of Engineering, Mathematics and Physical Sciences, University of Exeter, Exeter EX4 $4 Q F, U K$ \\ ${ }^{b}$ Department of Engineering Science, University of Oxford, Parks Road, Oxford, OX1 3PJ, UK ${ }^{c}$ \\ Department of Mechanical Engineering, Imperial College London, London, SW7 2AZ, UK
}

\begin{abstract}
The effects of debris particles in fretting contacts are substantial and are believed to play a key role in the difference in wear rates observed between fretting and full sliding wear. Studies of debris have shown that the effects can have detrimental or palliative effects on the parent surfaces. This work aims to explore this phenomenon through the study of fretting contacts of EN24-T (steel) and Ti-6Al-4V (titanium alloy). All combination pairs of these materials were tested in oxidative and non-oxidative atmospheres. Methods were developed to measure the wear rates throughout each test and corresponding 'time stamped' debris samples were analyzed. Vast differences were observed in the effects of oxygen on the wear rates of the two materials. Evidence suggests that the reason for this difference in the size of the particles in the contacts, not hardness.
\end{abstract}

Keywords: Fretting, Wear, Atmosphere, Debris, Oxide

\section{Introduction}

\subsection{Fretting wear}

Fretting wear is the removal of material from a surface under contacting pressure and small amplitude lateral displacements. It is a common limitation for the lifing of contacting components in industry [1]. Components are often fixed to one another through the use of fasteners such as bolts or rivets which apply very large normal loads and consequently large frictional forces to prevent rigid body motion. If these joints are subject to vibration, then low amplitude reciprocating wear may occur. Examples of common mechanical assemblies subjected to fretting wear include bearing races, shafts, turbine blade roots and electrical contacts $[2]$.

Fretting is usually defined by a limitation in the range of amplitude of relative displacement between reciprocating parts; the minimum value is not universally agreed upon in the literature but typical amplitudes are around $300 \mu \mathrm{m}$ [3]. Fretting wear requires some relative displacement between contacting surfaces, which is achieved when an applied lateral force exceeds the resistive friction force in the contact [4]. Fretting contacts differ from full sliding (large displacement amplitude) contacts in two key ways: first, fretting components 
are usually designed to be relatively fixed and so are unlubricated. Secondly, wear particles are less able to escape as the contact region remains at least partially covered [1].

As a result of these complications, the capability of models for fretting wear lags significantly behind those for sliding wear, which for many applications can be adequately predicted by the Archard law, published in the 1953 [5] and developed or modified in many ways since [6]. Methods based upon the 'Archard law' do not work well for prediction of fretting wear, possibly because they do not account for the effects of entrapped debris. An example of such a model is by McColl et al, which works well at lower loads but has significant error at higher loadings, attributed in part to debris [7]. Owing to the requirement for better lifing accuracy and thus design tools, there is a need for i) new models for fretting wear, and ii) experimental data on fretting wear, debris, and its influence on wear. Many components such as those in gas turbines operate at elevated temperatures and in complex gaseous environments. This paper concerns fretting wear, debris and the influence of gas environment on wear rates.

\subsection{Methods for analysis of debris}

Debris particles are known to occur with diameters over a large range from nm to $\mathrm{mm}$ [8]. Optical microscopy can be used only for the largest (micron and millimetre scale) particles, with SEM (Scanning Electron Microscope) and TEM (Transmission Electron Microscope) electron microscopy for everything else. Microscopy is often followed by automated image processing for size and shape data (since the number of particles is typically large), and EDS (electron dispersive spectroscopy) for elemental composition analysis. The way in which debris particles influence wear in a fretting contact is complex and may vary with contact pressure, particle size and substrate material [9], substrate and particle hardness (having both positive and negative effects on wear rates [10] [11]), wear mechanism [12] and contact geometry [13]. Since EDS only directly provides information on elemental composition and not the materials present, some researchers employ XRD (x-ray diffraction) in the analysis of debris [11] [14] [15] [16].

\subsection{The requirement for physics based debris models}

Much of the research on wear debris to date has been in the development of on-line monitoring systems, by means of which industrial processes can be constantly monitored for signs of severe wear through observation of the debris produced, eliminating the requirement for scheduled maintenance. Two papers by Peng et al, written almost 20 years apart[17] [18], describe how the same debris measurements are being applied in on-line monitoring, only now with better equipment. These measurements include area, fibre ratio, aspect ratio, fractal dimension and roughness among others. Papers by Kumar et al and Wu et al [19] [20], evaluate these methods, concluding that the capability and resilience of sensors, disagreement about failure conditions, and the requirement for expert subjective interpretation, limit the applicability of on-line monitoring. Development of these methods lies in the improvement of sensor technology and artificial intelligence methods such as neural networks to replace expert monitoring [19]. 
Even if it is difficult to apply on-line monitoring broadly in industry, the well founded relationships between wear severity and debris morphology, composition and colour, can be exploited in modelling. Done et al show that, even accounting for debris in a finite element model (by assuming debris are adhered to one of the first bodies), represents an improvement in accuracy over complete neglect of debris [21]. Others have explored the more computationally expensive option of DEM (discrete element modelling), which allows the employment of more physics and fewer geometry dependent empirical coefficients [22] [23]. These models require data on the morphology and composition of debris particles and information regarding the mechanisms by which debris particles interact with each other and the third bodies.

\subsection{Oxide debris and oxidation wear theory}

The availability of oxygen in fretting metal contacts enables the production of multiple possible debris compositions. Oxides are often quite different in their properties from their metals and so identifying the composition of debris is critical to the accuracy of models, as shown in the on-line monitoring research. A study by Peng et al used only colour for the identification of debris particles and reviews literature noting significant differences in wear rates of steel in the presence of black and red iron oxide [24]. These two oxides, black $\mathrm{Fe}_{3} \mathrm{O}_{4}$ and red $\mathrm{Fe}_{2} \mathrm{O}_{3}$, are the two most common oxides produced from iron at room temperature. The red oxide is the final oxidative state of iron at room temperature, whilst black oxide typically occurs during more rapid oxidation as a result of higher temperatures [25].

Experimental research on iron oxide debris had a focus on oxide compacted layers or "glaze layers". This was the result of agglomeration / sintering of debris particles into a layer on one or both of the first bodies in a contact and was identified as the reason behind the protective nature of iron oxides in wear contacts [26]. The work of Stott et al on oxide glazes noted, by measuring the electrical resistance across the two contacts, a correlation between oxide presence and reduction in wear rates / friction coefficients [27]. These authors described the method of glaze layer formation, comparing the process to hot-pressing, by which many ceramic products are formed. This process was determined to require small particles (10-50nm), of "almost any oxide or oxides", bonding with weak bonds, the nature of which is not stated. The work of Inman agrees with this and explored sintered oxide glaze layers occurring in contacts of nickel and cobalt based alloys [28]. Zhou et al sintered nano scale metal particles (10-200nm, mean size 30-40nm) of iron and nickel at room temperature through a cold-welding mechanism, showing that the potential to form a glaze layer in a wearing contact was independent of debris composition and required only a suitable size distribution [29].

It is important that DEM models capture the various ways in which oxide debris can affect wear rates, including their tendency to agglomerate, produce glaze layers, and abrade first bodies, and the conditions under which these effects occur.

\subsection{Effects of gas environment on wear rates and debris}

Whilst providing useful empirical data on wear in extreme conditions, studies of wear in various oxygen concentrations and vacuum indicate that there are very few universally true 
statements that can be made about the effects of oxygen availability. The literature generally agrees that for steel-steel contacts in air, the effect of oxygen is to reduce wear in the steady state [24] [26]. However the work of Begelinger et al on the effects of oxygen concentration in steel-silver contacts showed the inverse to be true, concluding that iron oxides were contributing to an adhesive wear mechanism [30]. Whilst some researchers have found vacuum conditions to accelerate wear by severe adhesive mechanisms (cold welding) [31], others have found that upon increasing the atmospheric pressure (and so oxygen availaility), wear rates of steel and titanium alloys on $\mathrm{Cu}$-Be alloy plates increased further [32]. Finally work by Akagak et al showed that large variations in wear rate and debris particle size are observed in vacuum, corresponding to the variation of the ratio of hardness between the two first bodies in the contact [33]. These inconsistencies in the effects of oxygen presence, and the different types of debris produced, indicate a requirement for data linking specific debris morphologies and compositions, to wear rates.

The intent of this work was to explore the debris particle parameters critical to modeling of fretting wear. Manipulation of the oxygen availability was used as a method to vary debris parameters independently of any other test parameter. This paper evaluates the impact of oxygen presence in debris particles in fretting wear contacts. The two materials studied were a steel (EN24-T) and a titanium alloy (Ti-6Al-4V), chosen for their prevalence in the literature and in aerospace component design.

\section{Methods}

The approach taken here was to develop a testing protocol capable of determining how the gas environment of a contact affected the type of debris particles formed and the wear rate as a function of cycle number. The test was to be undertaken on two materials, steel (EN24-T) and titanium alloy (Ti-6Al-4V), and in two gasses, air and argon. Wear debris was to be captured continuously during the test for analysis.

\subsection{Experimental rig and conditions}

The schematic in Figure 1 shows the experimental rig used in the investigation to be described. Three metal rods were arranged in a crossed cylinder configuration, wherein the vertical rod was displaced (shown in Figure 1 indicating $+/-0.3 \mathrm{~mm}$ ), and the two horizontal rods were held still but with a clamping force applied so they pinched onto the vertical rod. The two horizontal samples were supported in clamps on thin, wide cantilevers, providing a sturdy support with good compliance in the direction of the applied contact force (shown in Figure 1 left as black arrows indicating $100 \mathrm{~N}$ force), and relatively higher stiffness in the plane of wear. This allowed the horizontal samples to move towards one another during the test as the samples wore, yet to maintain a near constant contact force throughout. The contact force was developed by a pre-loaded spring assembly contained within a calliper, which itself rested on a set of bearings (Figure 1 right). This assembly, with near zero lateral resistance, ensured the same force was applied to both contacts. The spring is relatively long so that the small change in spring length over the course of a test resulted in $+/-1 \%$ 
about the nominal $100 \mathrm{~N}$ contact force. A bespoke miniature pancake load cell monitored the contact force.
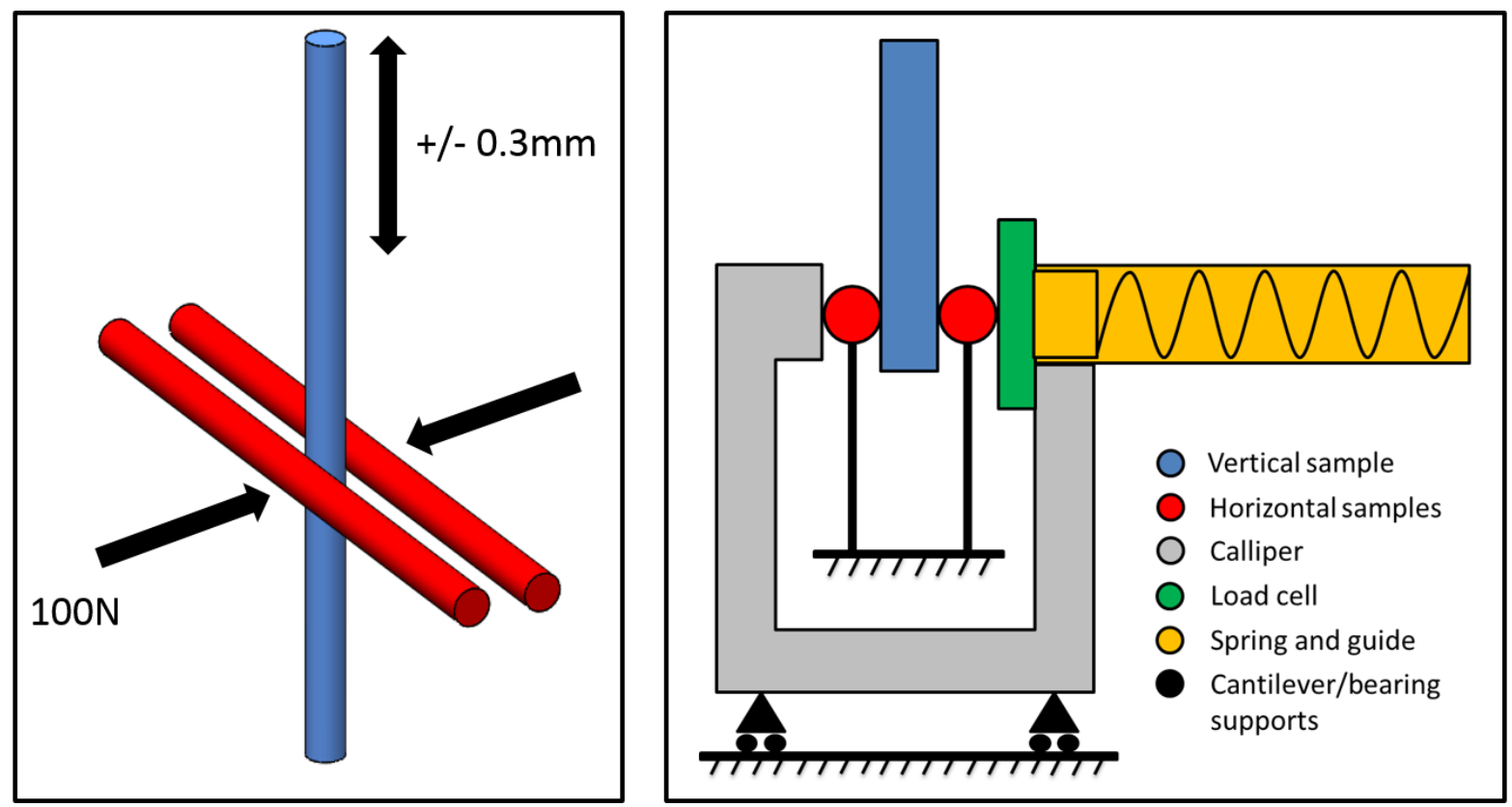

Figure 1: Left: A model of the 3 samples used and descriptions of their interactions. Right: A labelled schematic of the components employed in the wear rig

The vertical sample was fixed to a linear actuator of a universal mechanical testing machine (Instron 8872) which allowed control of the cyclic displacement amplitude and frequency, in this case $+/-0.3 \mathrm{~mm}$ at $5 \mathrm{~Hz}$. Three combinations of steel and titanium alloy were tested, i) steel-steel, ii) titanium alloy-titanium alloy, and iii) steel-titanium alloy. Each material pair was tested in air and argon atmospheres. Steel-steel in air was tested 9 times to determine the repeatability of the experiment. Other experiments were typically performed 3 times, twice in some cases due to hydraulic failures. The EN24-T steel is typically chosen for its wear resistance after heat treatment, and was supplied (by Steel Express, Wolverhampton, UK) in $10 \mathrm{~mm}$ rods containing $0.44 \% \mathrm{C}, 0.35 \% \mathrm{Si}, 0.7 \% \mathrm{Mn}$, $0.04 \%$ S, $0.035 \%$ P, $1.4 \%$ Cr, $0.35 \%$ Mo, $1.7 \%$ Ni [34]. The Ti-6Al-4V was supplied (by Ti-TEK ltd, Birmingham, UK) in $12 \mathrm{~mm}$ rods containing up to $0.08 \% \mathrm{C}, 0.05 \% \mathrm{~N}, 0.2 \%$ $\mathrm{O}, 0.125 \% \mathrm{H}, 0.4 \% \mathrm{Fe}, 6.75 \% \mathrm{Al}, 4.5 \% \mathrm{~V}$ [35]. EDS was performed on samples of these materials to confirm that their compositions lay within the expected ranges. Experiments were run for 10,000 cycles. Since the contact temperature is known to be an important parameter in the formation of debris particles, the local bulk temperature was measured [36]. Due to the low frequency and displacement amplitude, measured frictional heating was negligible (0.5 - $1 \mathrm{~W}$ of frictional power).

All rod samples were turned on a lathe to $8.3 \mathrm{~mm}$ nominal diameter then ground to $8 \mathrm{~mm}$ diameter. Steel samples had an average roughness value of $0.3 \mu \mathrm{m} \mathrm{R}_{\mathrm{a}}$, Titanium alloy samples had an average roughness of $0.8 \mu \mathrm{m} \mathrm{R}_{\mathrm{a}}$ measured on an Alicona G4 Infinite 
focus Optical 3D profilometer. The differences in roughness between the samples of the two materials was deemed to have a negligible impact on wear rate due to the initial high contact pressures in a Hertzian (crossed cylinder) contact. Vickers hardness tests were performed on the Titanium alloy and steel and returned values of 344 and $293 \mathrm{HV}$ respectively, which lie in the expected range for such metals [37] [34]. Before each experiment all samples were cleaned with acetone to remove any oil and grease surface containments. For any given test, the mechanical conditions are assumed identical for each of the two contacts due to the design of the loading rig described in figure 1.

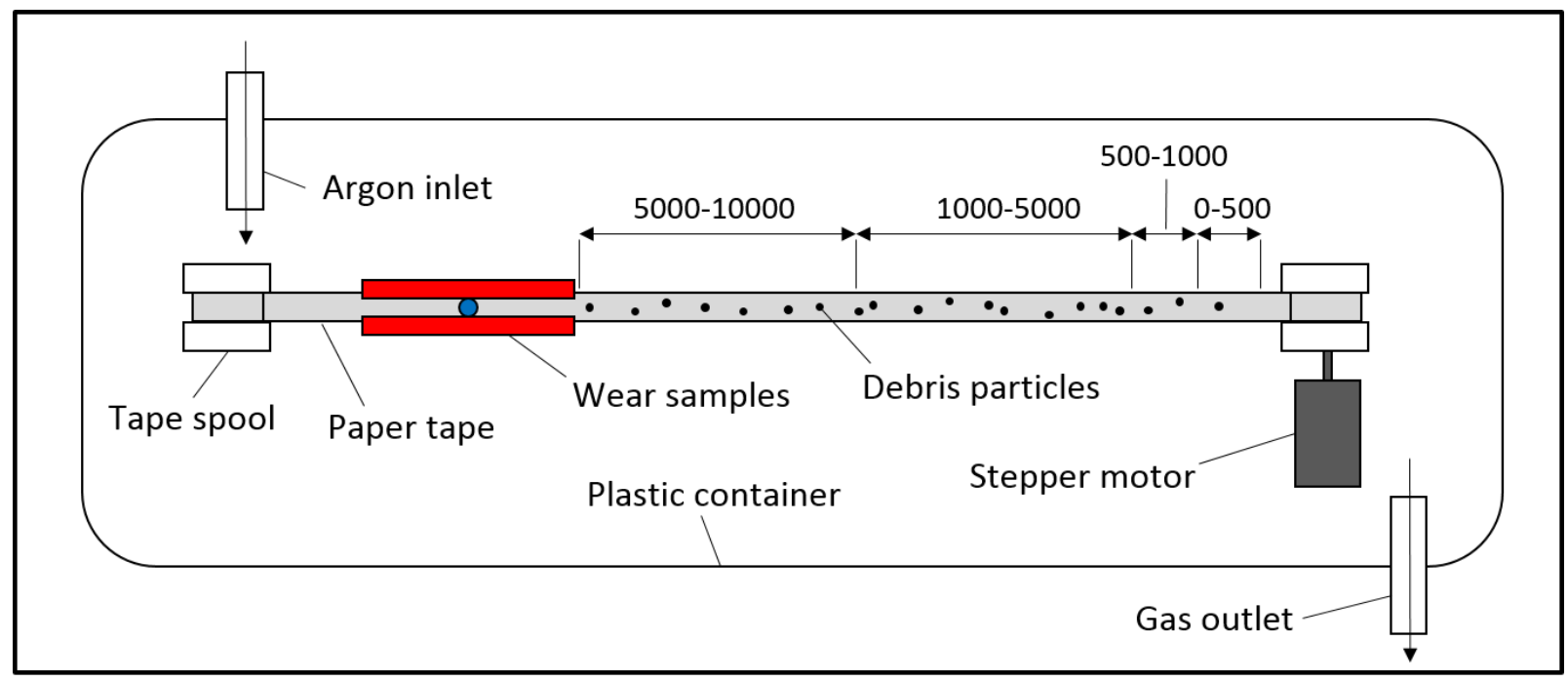

Figure 2: Schematic of the atmosphere control and debris collection apparatus

\subsection{Capture of debris and control of oxygen availability}

In order to capture the debris produced throughout the test for analysis, a capture system was developed. A narrow paper tape was located beneath the contact zone and just fitting within a gap in the calliper. It was drawn out of a spool at a constant rate by a stepper motor, ensuring that a time (and therefore cycle number) data could be associated with specific debris. Upon completion of a test, this tape was cut into pieces corresponding to the cycle ranges $0-500,500-1000,1000-5000,5000-10000$. These cycle ranges were chosen based upon the results of preliminary tests with the purpose of catching the debris types produced during mild, transition and severe stages of wear when fretting steel samples in air. The debris on these tapes was stored in acetone and transferred to TEM grids for microscopy. The test rig was sealed within a plastic enclosure to allow for control of oxygen availability to the contact zone by the introduction of argon gas, shown in Figure 2. This enclosure contained both the contact region and the entirety of the debris capture apparatus to allow collection and analysis under the controlled gas environment. A constant input flow of argon was maintained to compensate for any leaks in the plastic enclosure. Prior to sealing, the samples were cleaned with a paper cloth and acetone to remove surface oxides and oils, until their surface became bright and reflective. Argon gas was fed into the enclosure until an 
oxygen monitor (KANE250 combustion meter) located internally, read $<0.2 \%$ oxygen $(<1 \%$ of the typical partial pressure in a laboratory). Oxygen levels were maintained at this level for the duration of the Argon experiments, by the adjustment of the argon flow rate.

\subsection{Calculating worn volumes and contact areas from measured worn depth}

The crossed cylinder experiment rig employed an LVDT (Linear Variable Differential Transformer) to measure advancement of the end of the spring providing the contact force in the calliper. This measures the total depth of the two wear scars on the sides of the vertical rod. In order to calculate the volume of worn material from the wear depth, a preliminary correlation was made for 31 samples in which the worn volume was measured accurately using an optical profilometer and plotted against wear depth as measured via the LVDT, over a range of cycle numbers from 50 to 10,000. The wear scars were analysed using an Alicona G4 Infinite focus Optical 3D profilometer. This produced micrographs of high field depth and 3D surface data with a claimed vertical resolution of $1 \mu \mathrm{m}$ and lateral resolution of $5 \mu \mathrm{m}$. An algorithm similar to that described by Pearson et al [38], was employed to calculate the volume lost from the measured scar. The micrographs obtained, exemplified in Figure 4 (top left), were measured to find the contact areas corresponding to the wear depths recorded.
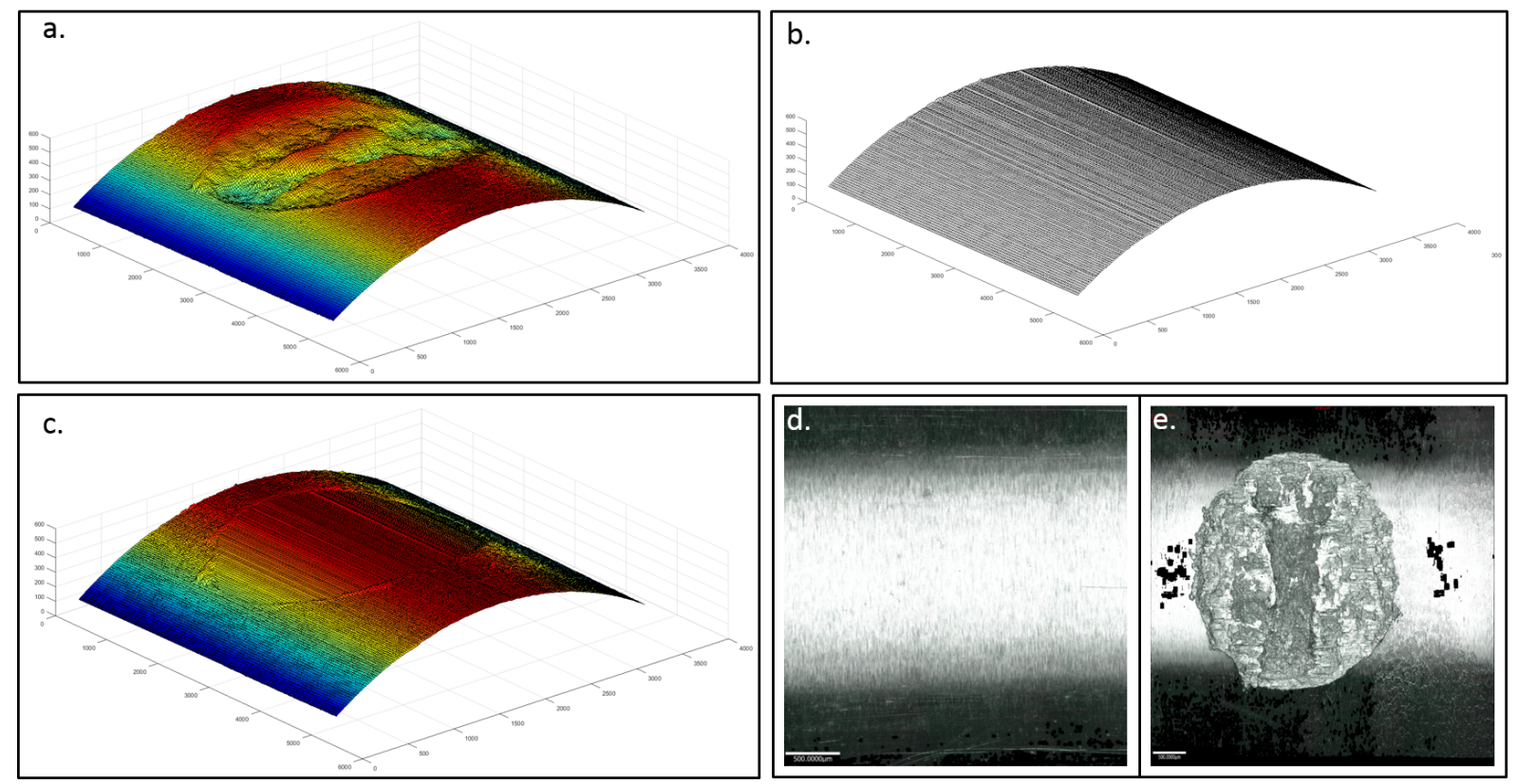

Figure 3: Data obtained by the profilometry of a worn sample: (a) A surface plot of the 3D data of the scar and surrounding region. (b) The approximated unworn surface formed by the interpolation between measured unworn profiles at either end of the scar. (c) The original worn profile and reference profile plotted together. (d)A micrograph of an unworn region. (e) A deep field micrograph of the scar.

To calculate the worn volume from the profilometer data of wear scars, surfaces conforming to the original (unworn) surface profiles were fitted, and the difference between these 
surfaces was calculated. The reference surfaces were set up by interpolating between unworn section profiles at either end of the wear scar with linear best fits which then form a surface, as shown in Figure 3 (b)and (c). The volume differences between the interpolated and worn surfaces were calculated by trapezoidal numerical integration. The presence of material above the interpolated surface, possibly as a result of material transferral or plasticity was disregarded, i.e. it was not included in the calculation of worn volume. This definition of "worn volume" is different from that described by Pearson et al, who described it as the sum of the volumes removed and the volumes transferred or moved by plasticity [38].

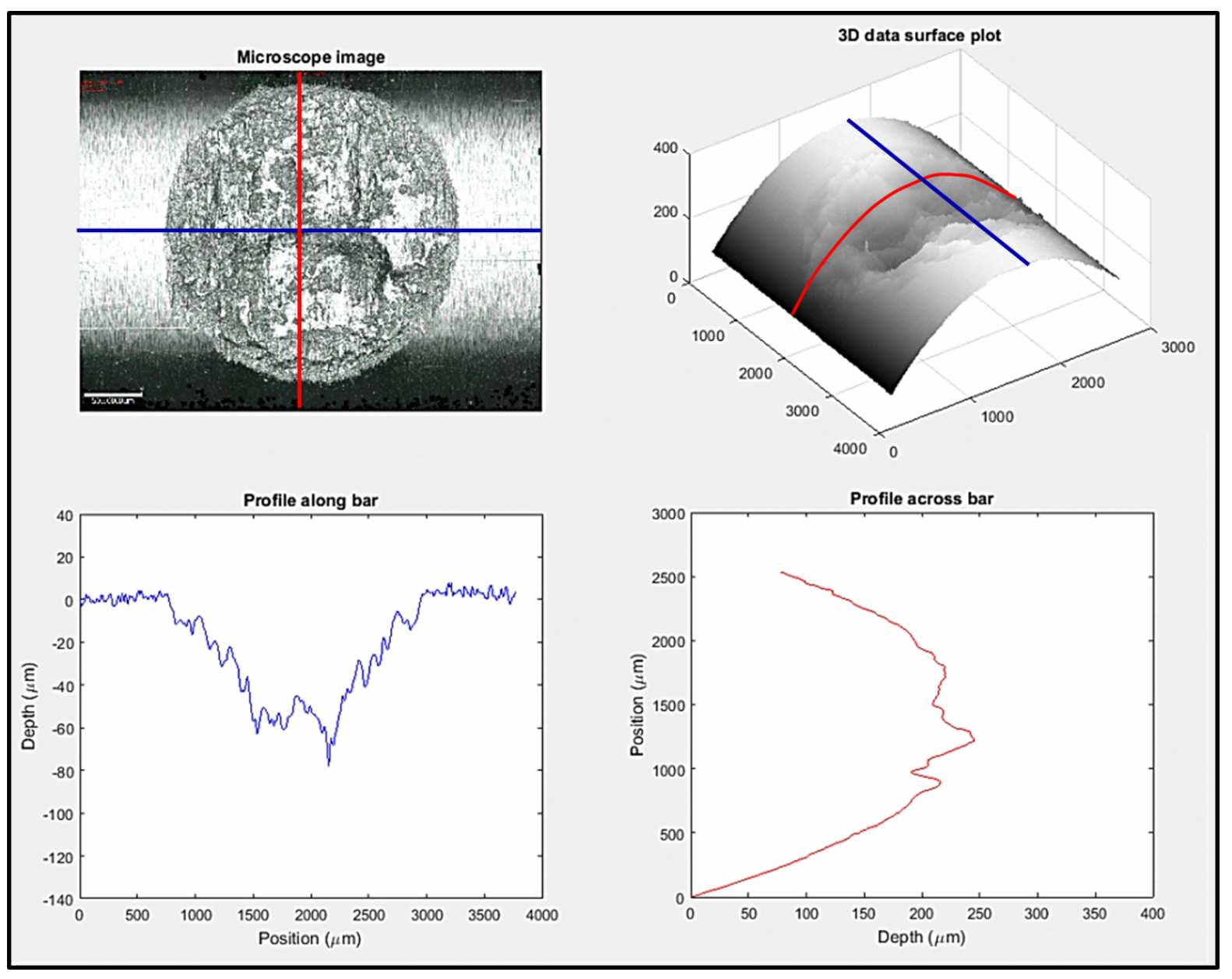

Figure 4: Top left: Deep field micrograph. Top right: Profilometer surface data. Bottom: Axial (left) and circumferential (right) scar profiles on a horizontal sample (steel on steel in argon).

In evaluating the accuracy of this algorithm and scanning technique, it was applied to unworn surfaces (known volume loss of zero). A worn volume of between 0.002 and $0.005 \mathrm{~mm}^{3}$ was calculated for clean surfaces. The average volume lost for a test after 10000 cycles was $0.238 \mathrm{~mm}^{3}$ and the lowest volume recorded in a test was $0.035 \mathrm{~mm}^{3}$ after 100 cycles. Errors with this method will clearly be relatively larger when estimating small volume losses, however this error is less than $5 \%$ for all measurements past 1000 cycles. A 
polynomial was then fitted to these data (third order to correspond with a length to volume conversion), displayed in figure 5. This polynomial was then used to plot wear volume vs cycle number for the experiments discussed in this paper. These plots can be interpreted to give the wear rates at varying stages of the experiment, throughout the development of the contact. Algorithm accuracy was once again evaluated by comparing the measured and estimated worn volumes of the samples. The average error across the whole data set was $21 \%$ however much of this error was in the estimate of smaller volume losses. The average error for estimates of volume with a measured volume of more than $0.1 \mathrm{~mm}^{3}$, was $11 \%$.

\subsection{TEM, EDS and associated methods}

After debris samples had been collected, they were sonicated at $40 \mathrm{kHz}, 180 \mathrm{~W}$ for 20 minutes to separate agglomerates so that particles could be viewed and analysed individually as much as possible. Particles were then dispersed by a pipette bubbling through the acetone, several drops of which were then pipetted onto a copper/carbon TEM support grid, 400 mesh size. The debris was then viewed in a JZOL 2100 TEM/EDS using an acceleration voltage of $200 \mathrm{kV}$. This method is typical for the analysis of nanoparticles, although since the samples must be dry to observe them in a vacuum, agglomeration is common during deposition onto grids [39].

\subsubsection{EDS oxygen quantification}

Carbon grids used to support the samples are known to contain oxygen. Since the measurement of oxygen concentration in the debris is of importance in this study, preliminary tests were undertaken to identify approximately this oxygen content so that it could be subtracted from subsequent measurements. The number of counts of oxygen detection varies with the area of grid exposed, and this area could not be kept constant due to required changes in magnification, so no absolute value could be used. A total of 16 scans were performed across 4 grids to find the average ratio of oxygen to carbon counts, as negligible quantities of carbon are present in the materials studied. The result was 0.03 counts of oxygen per count of carbon with a coefficient of variation of 17.5. The corresponding number of oxygen counts from the scans of debris were removed from the data sets. This makes a negligible difference for tests conducted in air but is significant for the analysis of low oxygen atmosphere data.

The purpose of the EDS measurements taken here was to identify the ratio of oxide to metal, in debris particles from the experiments. This ratio, in conjunction with a particle size ratio, can be used in DEM wear debris models. The oxides assumed in the calculation of these ratios are $\mathrm{Fe}_{3} \mathrm{O}_{4}$ and $\mathrm{TiO}_{2}$, for EN24- $\mathrm{T}$ and Ti-6Al-4V respectively. $\mathrm{Fe}_{3} \mathrm{O}_{4}$ is expected over the other common iron oxide $\left(\mathrm{Fe}_{2} \mathrm{O}_{3}\right)$, due to the black colour of the debris. Whilst there are several possibilities for the type of oxide produced from titanium, $\mathrm{TiO}_{2}$ is by far the most common air-formed oxide. This $\mathrm{TiO}_{2}$ passive layer on $\mathrm{Ti}-6 \mathrm{Al}-4 \mathrm{~V}$ has been thoroughly studied in medical research literature for its biocompatibility in implants [40].

\subsubsection{Particle size analysis}

Images were taken of random particles viewed through the TEM, as in many samples thousands of particles could be identified. Particles or agglomerations in which boundaries 
could not be clearly distinguished were disregarded. These images were then imported into ImageJ software [41], converted to black and white images and then a manual threshold applied to produce a binary image. The threshold value was chosen to produce an image with particle boundaries that were judged to be most similar to the original image. This is similar to methods described here [42]. Once the particle boundaries had been identified their areas were recorded by pixel counting. Since the majority of particles had low aspect ratios, they could be realistically approximated as spheres of the same cross sectional area.

\subsection{Dissipated energy calculation}

The loads and displacements recorded by the Load cell and LVDT were used to produce hysteresis loops for each cycle. As described by Fouvry et al, the area of these loops is used to calculate the dissipated frictional energy per cycle [43]. The literature on wear commonly associates change in wear rates with changes in friction [32]. Dissipated energy, calculated in this way, is used here as a metric of friction as it is a function of the average friction.

\section{Results}

\subsection{Wear depth to wear volume calculation}

The amount of wear during tests was quantified via the LVDT measurement of advancement of the spring applying the contact force. The relationship between the depth of wear and the volume of worn material is shown in figure 5. The fitted coefficients of the best fit cubic polynomial function is given in equation 1 , which was used to calculate worn volume from LVDT measurements.

$$
V=1.555 D^{3}+5.716 D^{2}+0.9746 D
$$

Where $\mathrm{D}$ is the LVDT measurement in $\mathrm{mm}$ and $\mathrm{V}$ is the corresponding volume loss in $\mathrm{mm}^{3}$. Equation 2 gives the fitted linear relationship between the measured wear depth and wear scar area $\mathrm{A}$, in $\mathrm{mm}^{2}$.

$$
A=12.12 D+0.6827
$$




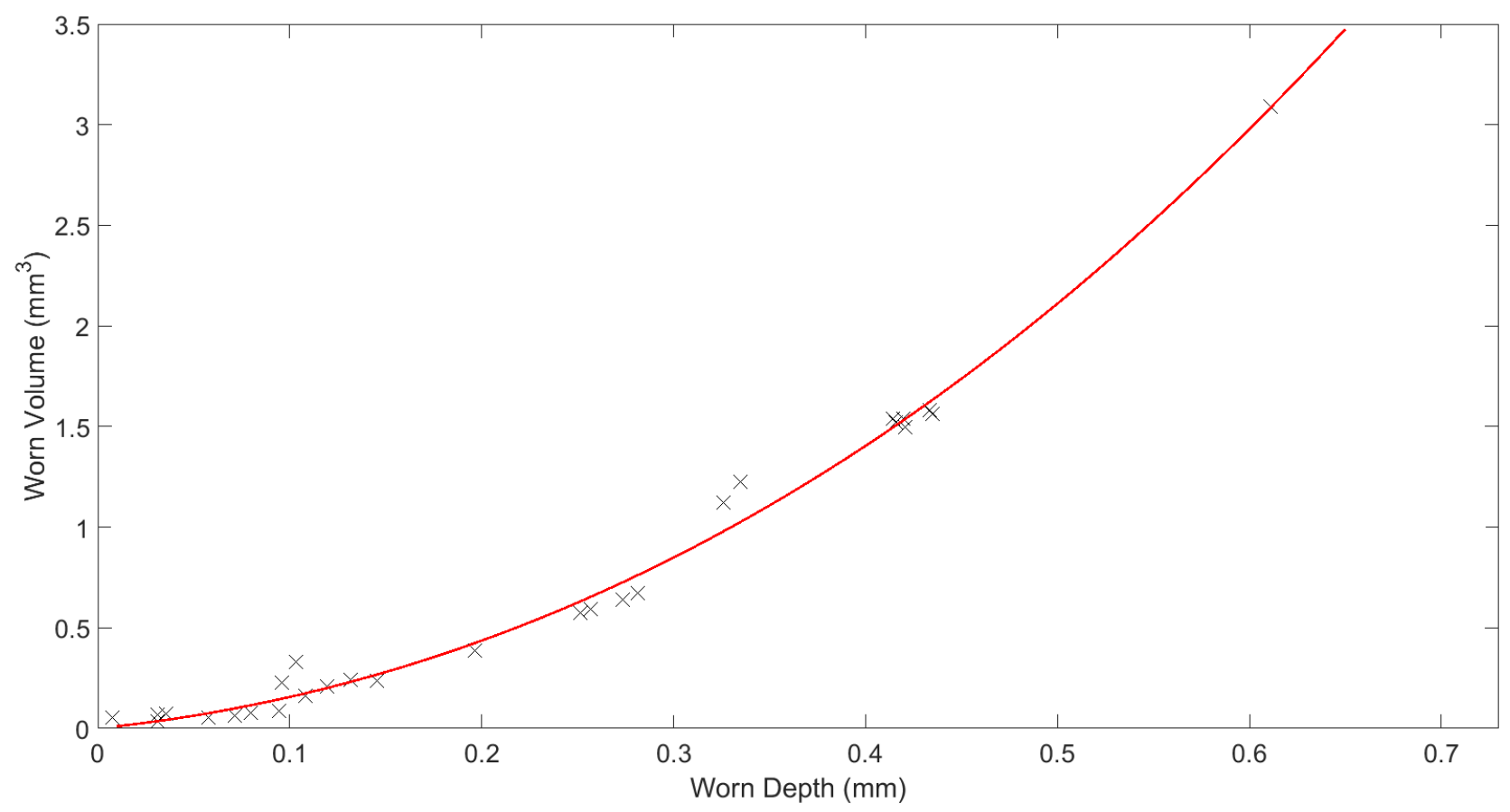

Figure 5: The polynomial best fit used to relate worn volume to measured wear depth. These samples (including steel-steel, titanium-steel and titanium-titanium) were tested up to a specific cycle number (between 100 and 10,000 cycles), then removed for measurement of worn volume via the profilometer. 


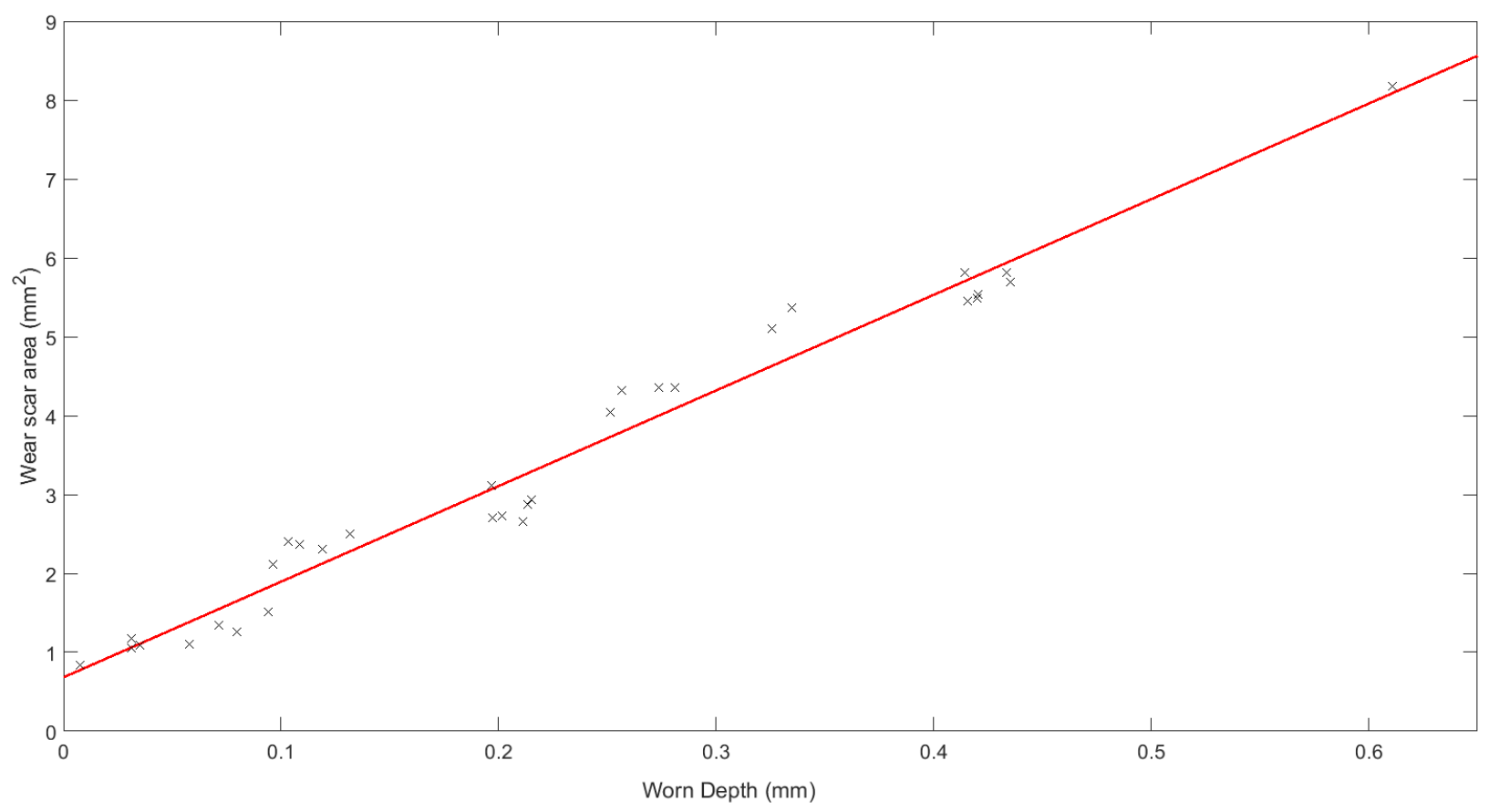

Figure 6: The linear best fit used to relate wear scar area (used in the calculation of nominal contact pressure) to measured wear depth. The same samples were used as for the calculation of the wear volume calculation polynomial in figure 5. The wear scars of these samples were measured by light microscopy.

\subsection{Repeatability}

In evaluation of the repeatability of the rig, 9 tests were performed on steel-steel in air, the results of which are given in figure 7 . The standard deviation as a percentage of the mean (of the final worn volume of these tests) was $7 \%$. 


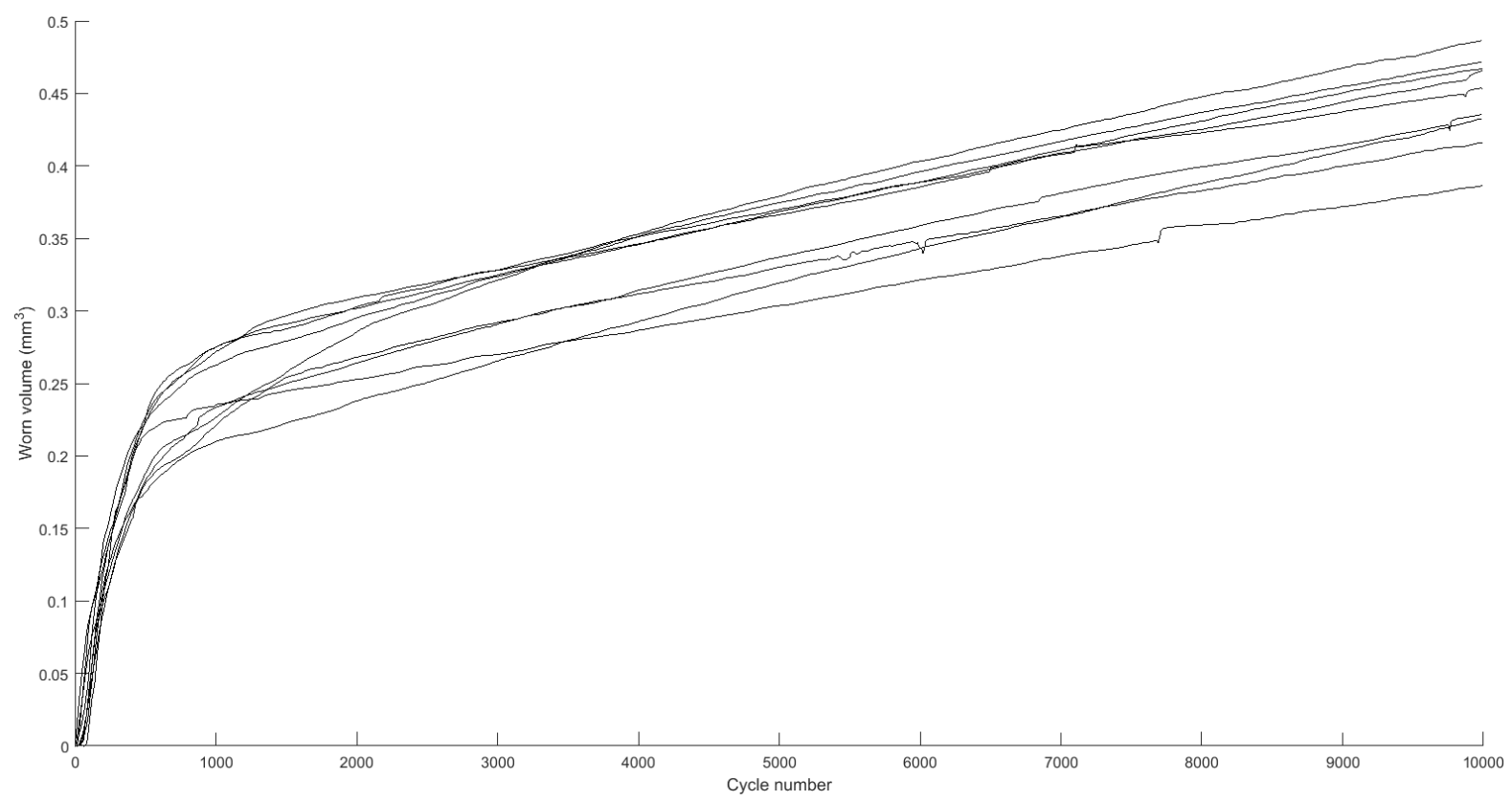

Figure 7: Results of all steel-steel tests in air, Worn volume vs Cycle number. Used to calculate the repeatability of the rig.

\subsection{Wear volume with material and atmosphere}

The progression of wear with cycle number for all experiments is shown in Figure 8. Some tests exhibit an initially high rate of wear followed by a transition into a more steady regime, whilst others show no such transition. High linear wear rates are observed for titaniumtitanium and titanium-steel in air, whilst very little wear occurred between the same material pairs in argon. Figures 9 and 10 show the wear rate plotted against cycle number and the wear rate plotted against the estimated nominal contact pressure, respectively.

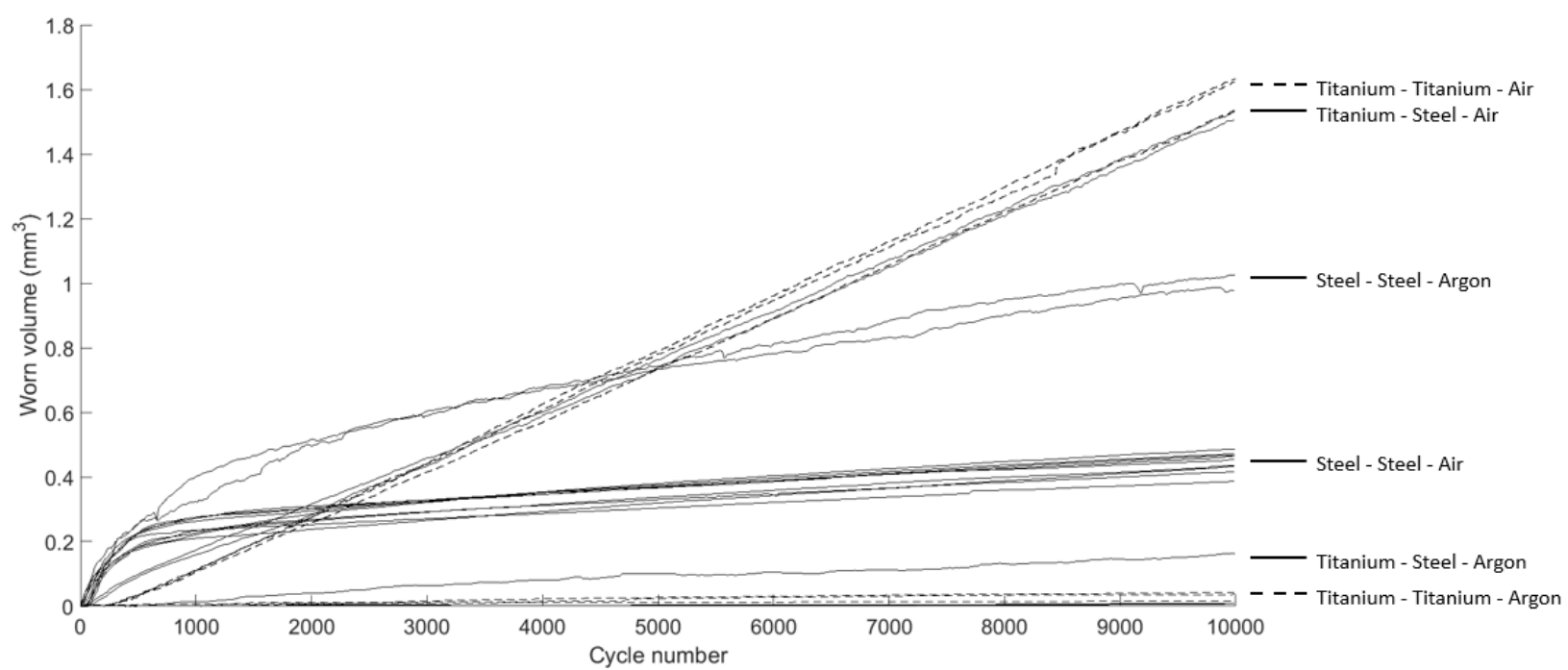

Figure 8: The progression of wear with cycle number for each of the 6 experiments. 


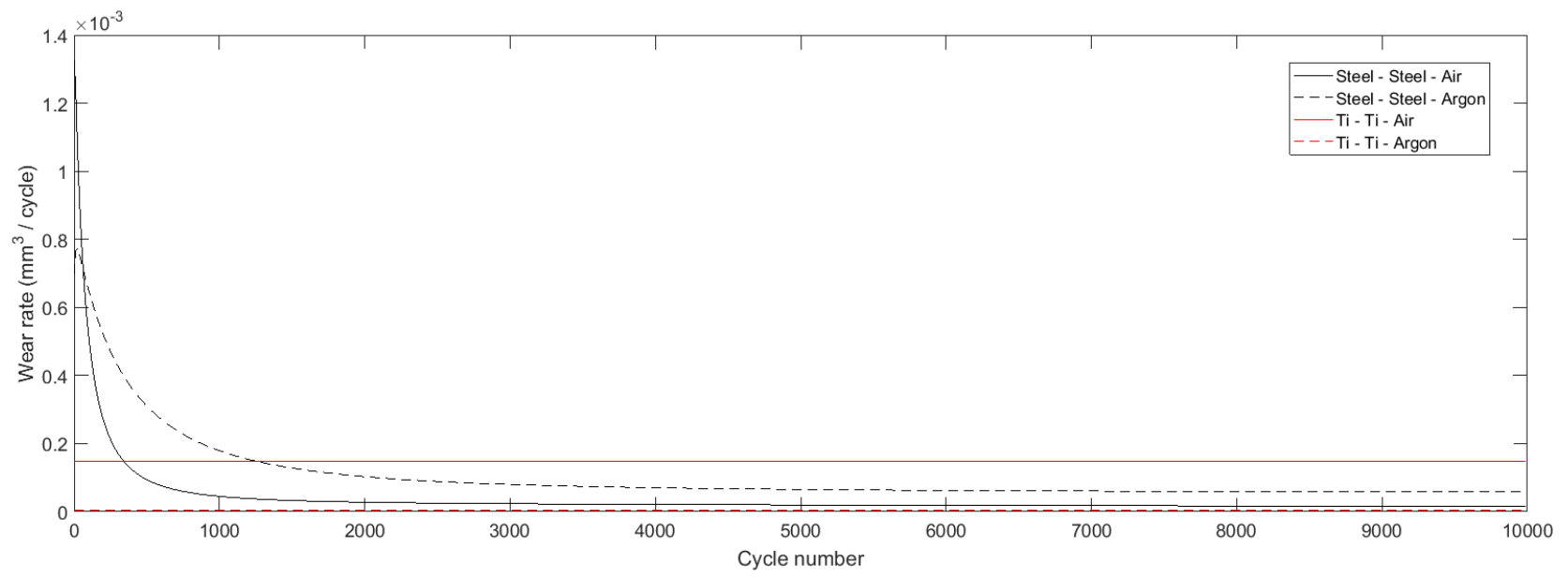

Figure 9: Wear rates plotted against cycle number, found by the numeric differentiation of polynomials fitted to graphs in figure 8

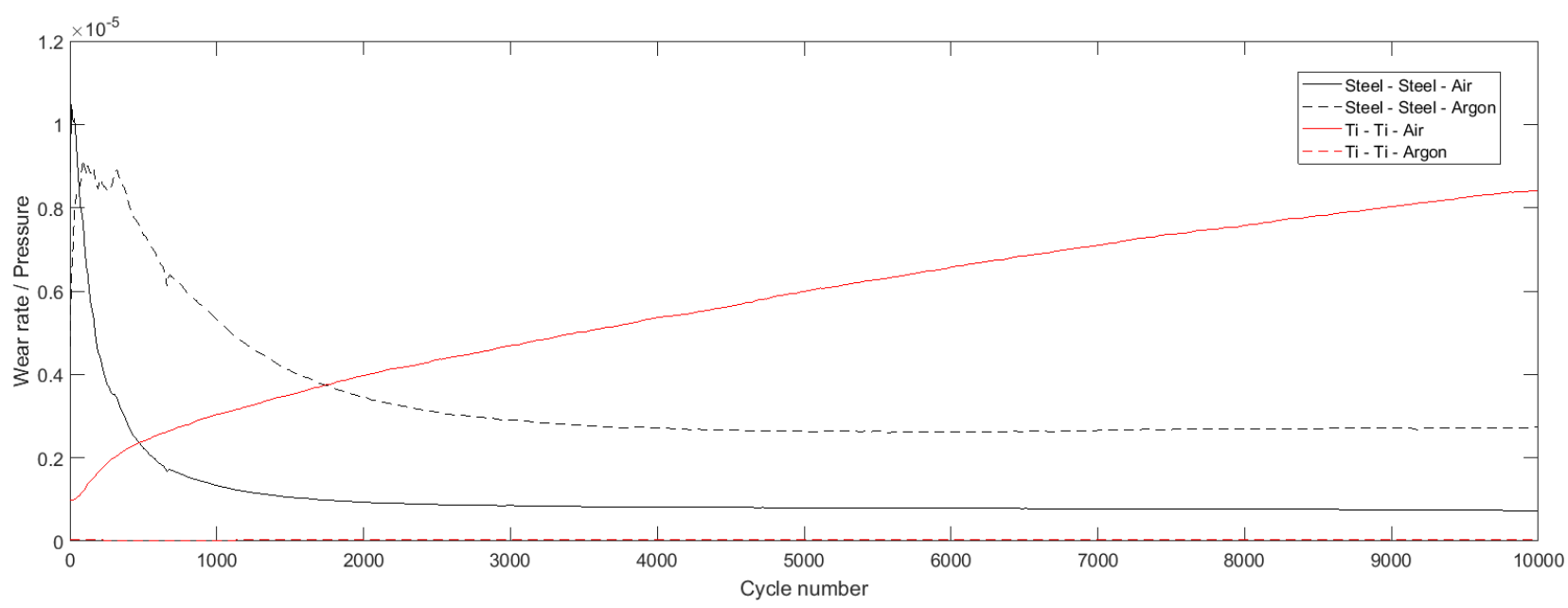

Figure 10: Wear rate per unit pressure (estimated at the time from the wear depth), plotted against cycle number.

\subsection{Debris size distributions}

The size distributions of debris samples taken from the experiments are graphed below. Where possible, $(\mathrm{x})$ markers are placed to indicate a data point, to aid visualisation of the relative density of the data within the distributions. They are, however, omitted in data sets with large sizes $(\mathrm{n}>500)$. Through microscopy of debris from the steel-steel tests at various magnifications, particles of two distinct size ranges were identified, separated typically by three orders of magnitude; consequently plotting them within the same distribution would impede comparison. For the sake of this comparison, these data have been graphed on 3 sets of linear axes. The first, Figure 11, shows the size distributions of the large debris particles from steel-steel tests. Figure 12 gives the distributions for the smaller debris particles in the 
same tests and Figure 13 compares all distributions available for the titanium-titanium and titanium-steel experiments, in which this small size range was not observed.

\subsubsection{Steel on steel test debris}

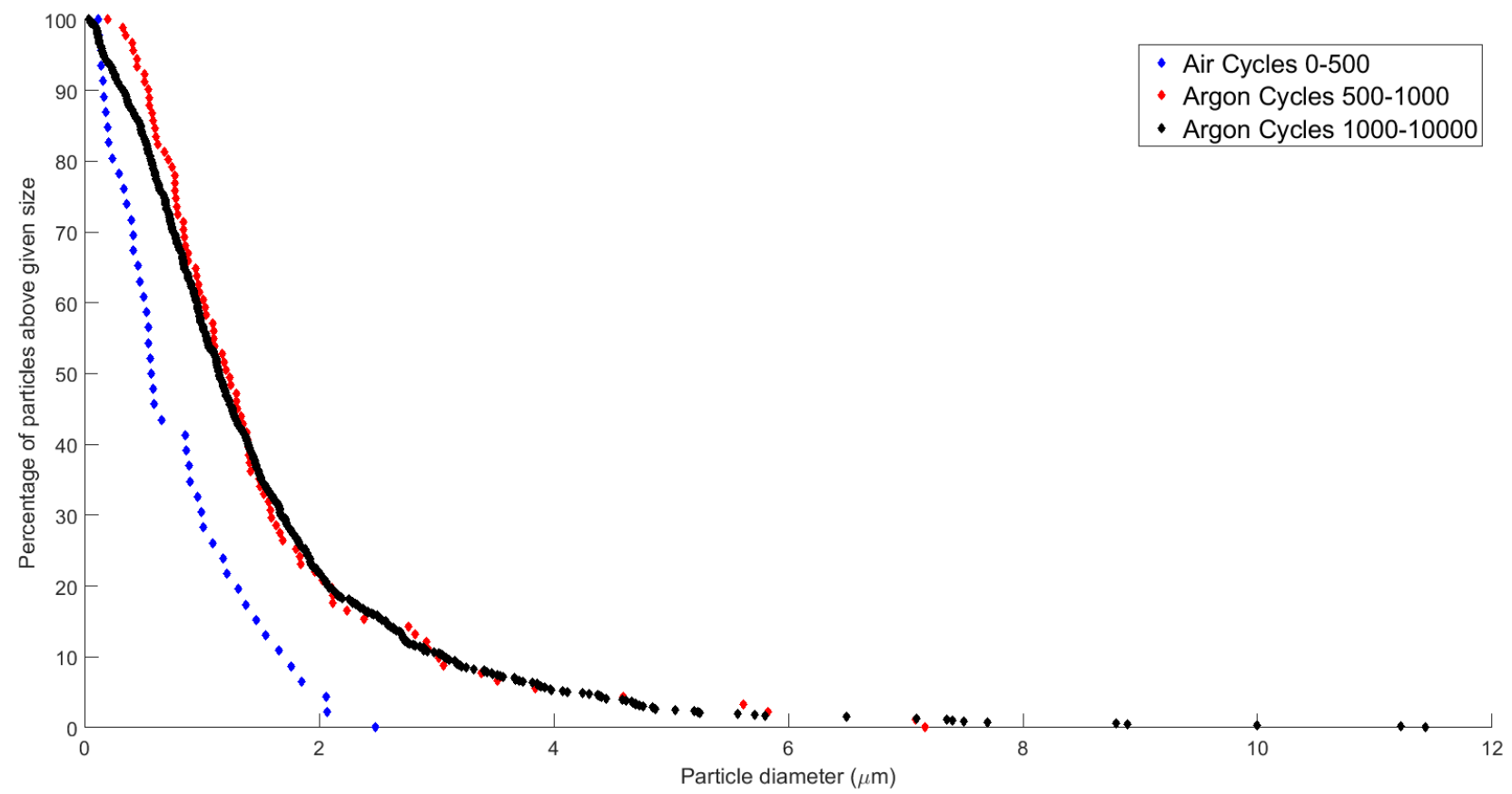

Figure 11: Steel metal debris size distributions. Mix of air and argon debris sets containing steel particles sufficient in number for analysis 


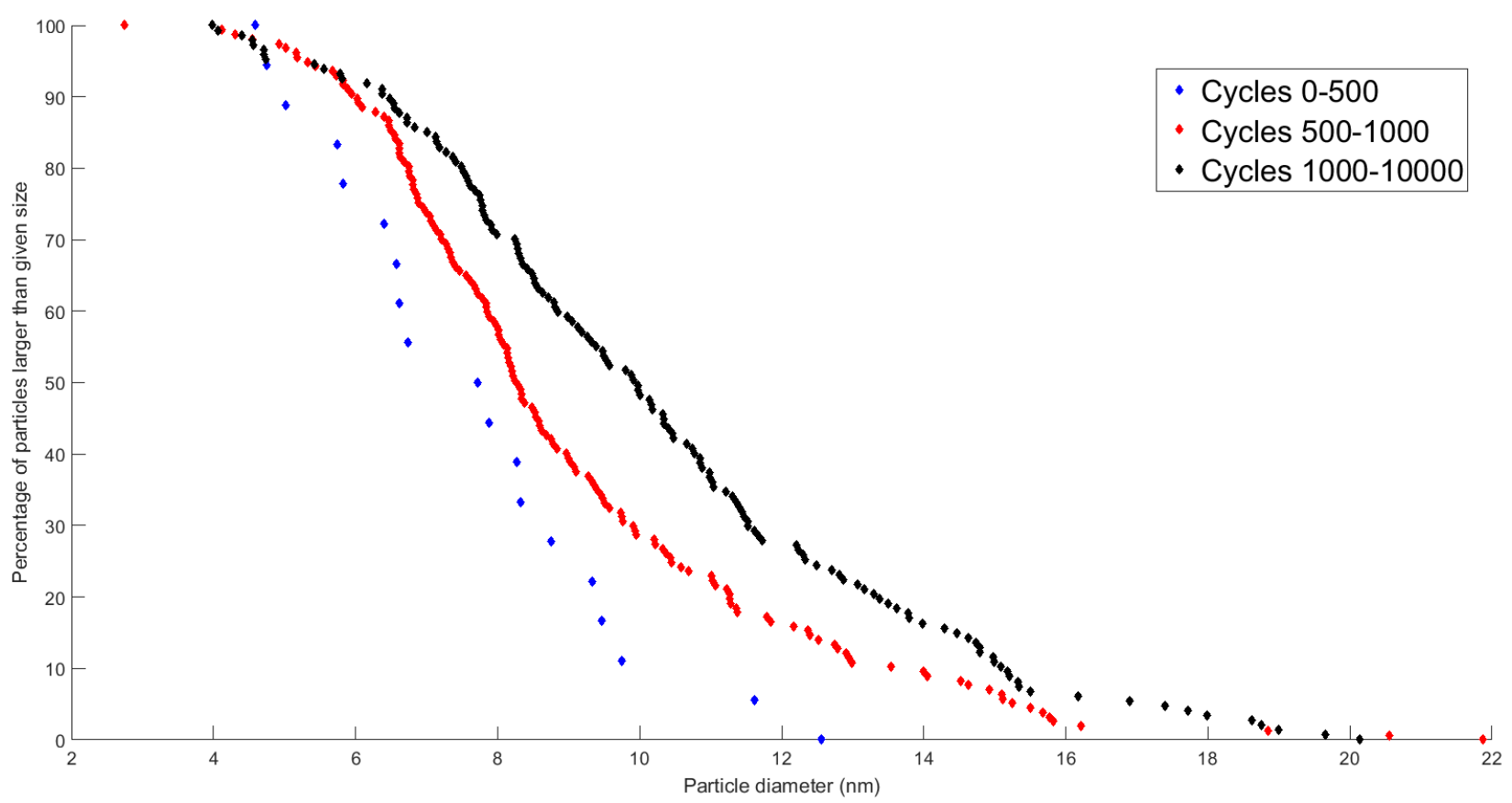

Figure 12: Steel oxide debris size distributions. All debris from steel-steel-air tests

\subsubsection{Ti-6Al-4V and mixed material test debris}

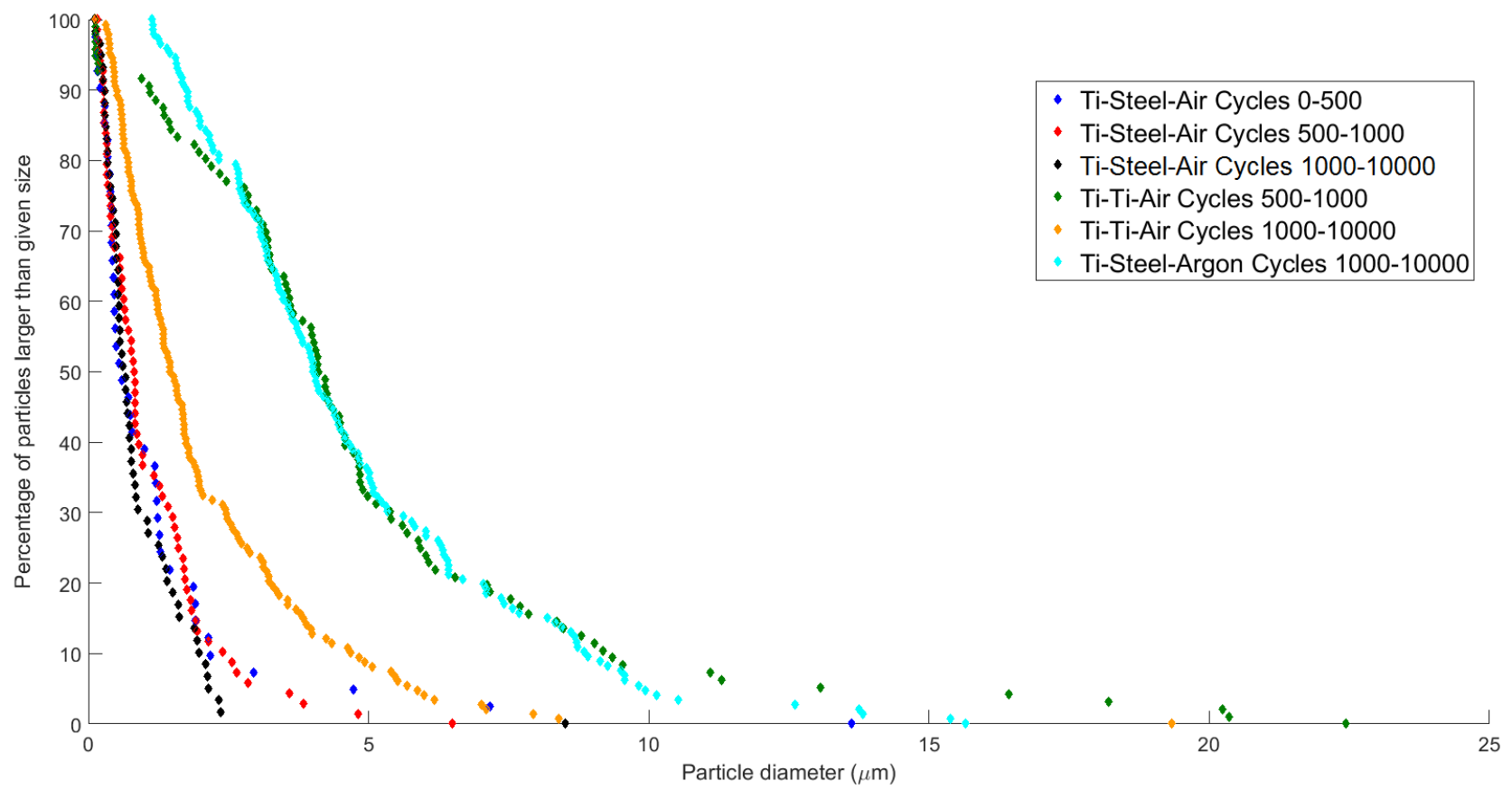

Figure 13: Titanium on titanium and mixed material in air debris size distributions. Most argon tests yielded insufficient debris particle quantities 


\subsection{EDS of steady state particles}

EDS results were recorded for all samples taken. The low cycle data sets had much higher variation in elemental composition, and fewer particles to analyse. The steady state (1000-10000) sample EDS data for all tests are presented in figure 14, for which many particles were available for measurement. These charts present the average ratio of oxygen to iron/titanium from each test for comparison to the ratio required to oxidise all of the metal present (right). For the titanium-steel tests, it is not possible to know from EDS to which of the metals present the oxygen is assigned (or by which ratio). Consequently, the charts given for these tests show the two extreme possibilities: that all the oxygen counts are from iron oxide or that they are all from titanium oxide.

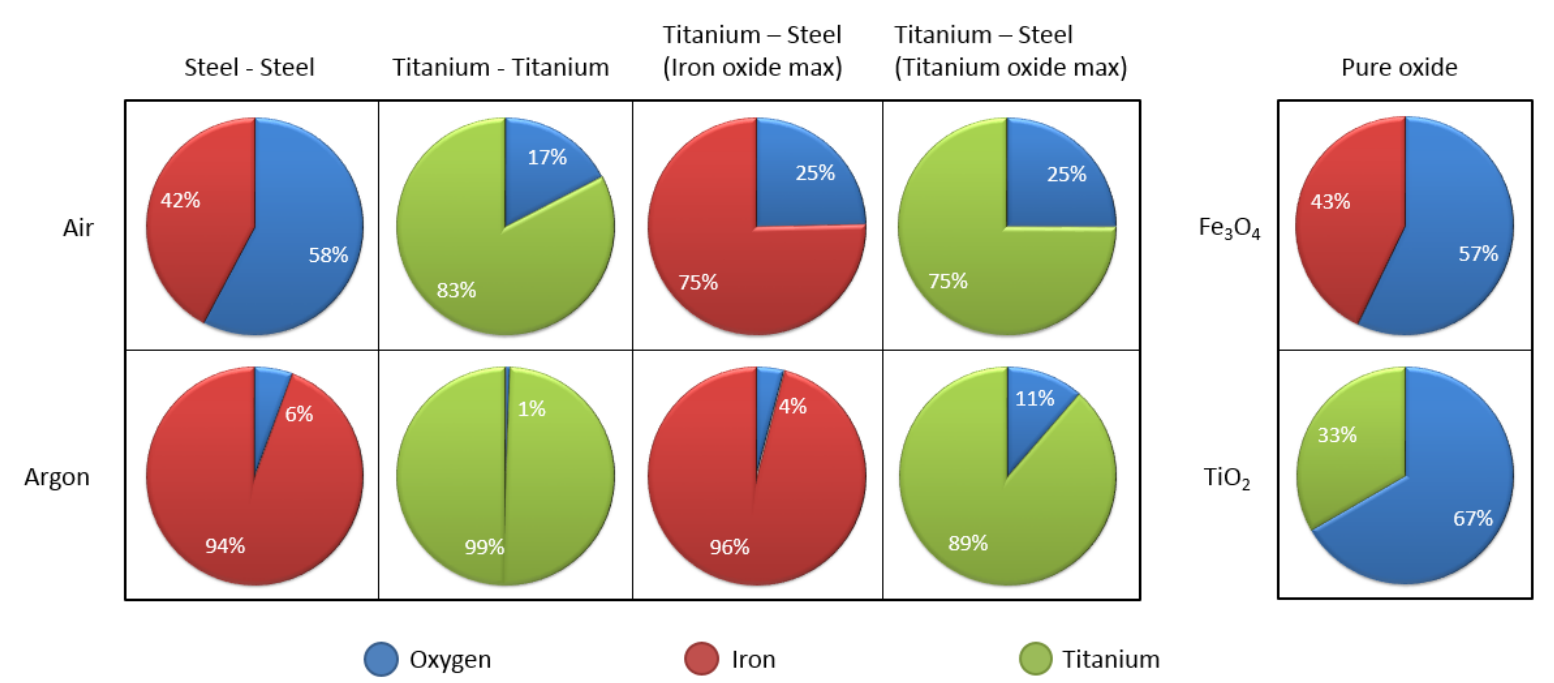

Figure 14: Ratios of oxygen counts to metal counts in steady state (1000-10000 cycle) wear debris, from processed EDS data

Considering the steel-steel tests, EDS scans over large numbers of debris particles can provide a measurement of the ratio of oxide to metal within a sample. This will not, however, provide any information as to the location of this oxygen, be it in agglomerations of oxide debris particles, oxide particles adhered to the surface of metal particles, or simply as a surface oxide on metal particles. Localised EDS scans of low cycle samples revealed that the bulk of this oxygen is located in agglomerations of smaller $(5-20 \mathrm{~nm})$ particles, in agreement with literature on steel debris. TEM micrographs in figure 15 shows the morphological differences between the two particle types. 

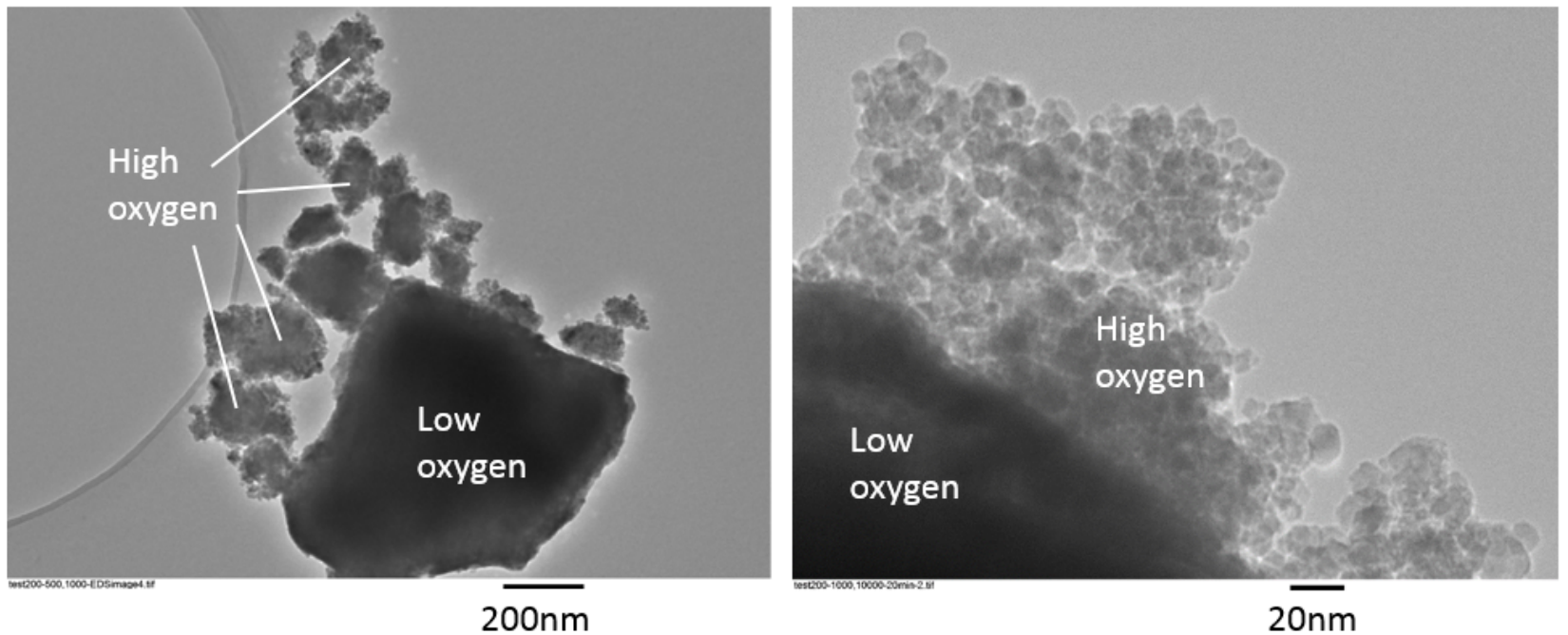

Figure 15: TEM micrographs of debris particles recovered from steel-steel-air tests. The left hand image shows how agglomerates of oxide particles can be visually distinguished at low magnification, by their transparency and morphology. The right hand image exemplifies the differences between the two particle types, at high magnification.

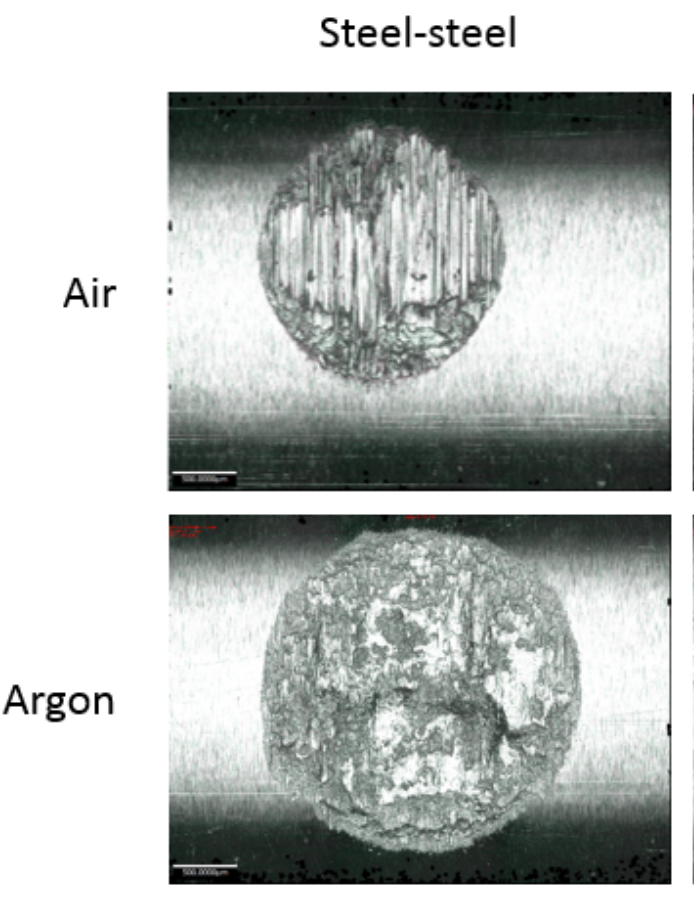

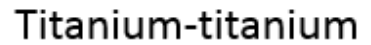
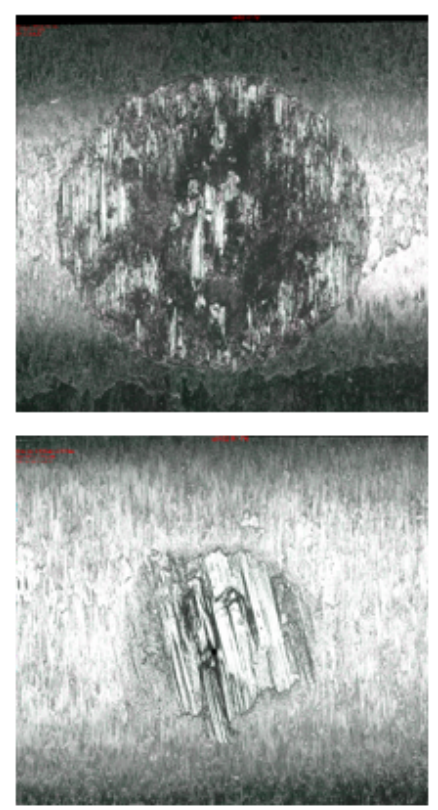

Titanium-steel
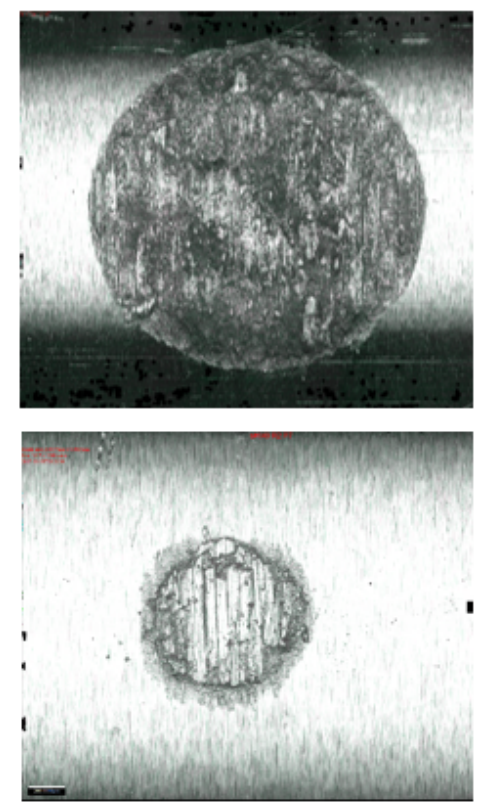

Figure 16: Example variable focus micrographs of a wear scar on the horizontal sample from each of the 6 experiments 


\subsection{Friction and Dissipated energy vs wear rate}

The cumulative dissipated energy is plotted against cycle number in Figure 17. All graphs are highly linear for the entire cycle range. With the exception of steel-steel-argon, the dissipated energy per cycle is very similar for all tests. The is no consistent correlation between the volumetric wear rate presented in Figure 8, and the energy dissipated for these tests.

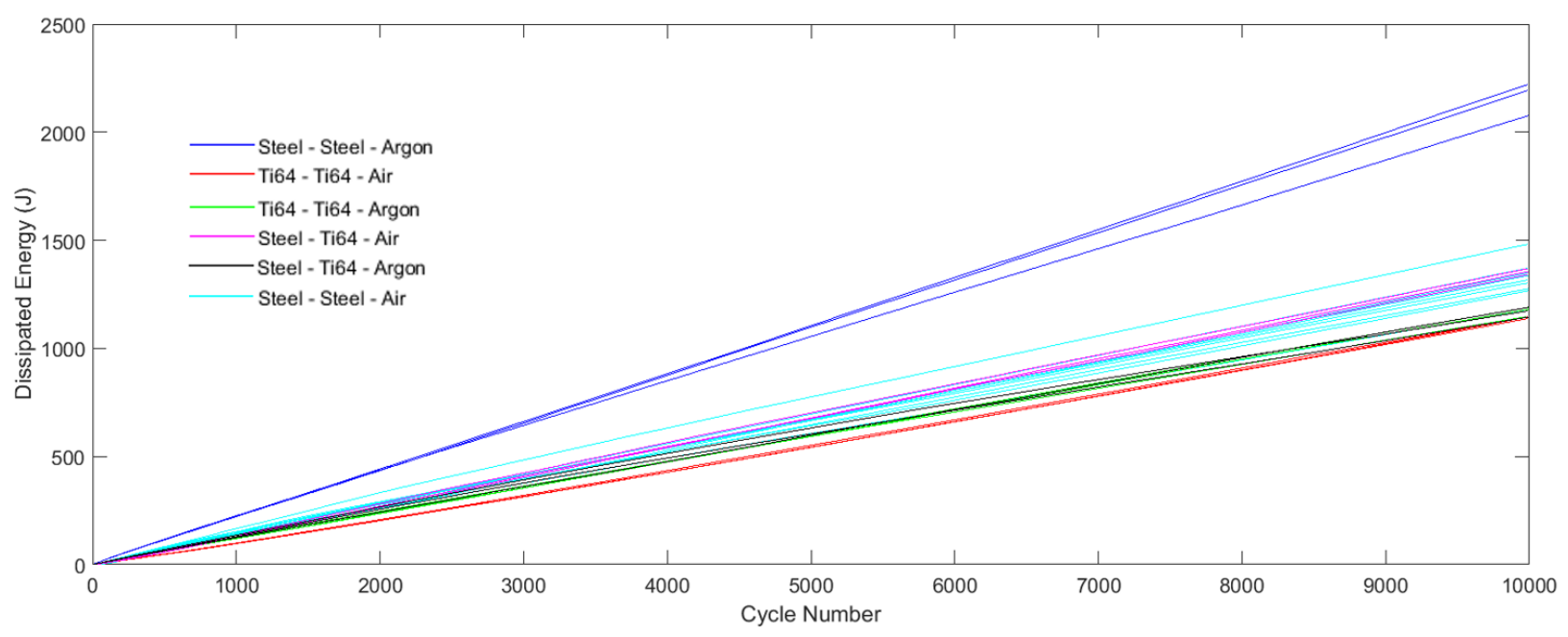

Figure 17: Plots of dissipated energy

\section{Discussion}

\subsection{Validation}

Figure 7 displays the results of the 9 steel-steel-air tests conducted to establish the degree of repeatability of the test rig. The standard deviation of the final worn volumes of these tests was $7 \%$ of the mean. Considering the differences in worn volume observed between the different experiments, displayed in Figure 8, this degree of repeatability is adequate to make clear comparisons. The bilinear nature of these graphs is in agreement with the literature for steel on steel contacts [44] [45] [46]. Furthermore, it was found that the average difference in worn volume between the two contacts in each test was within $2 \%$ of the total worn volume, so there is no consistent and significant difference between the two contacts. The apparatus developed to control the oxygen availability in the contact was sufficient to reduce repeatably the oxygen concentration to $0.2 \%$ as measured by the combustion meter. This reduction in oxygen was sufficient to prevent the majority of debris oxidation as shown in figure 14. Oxygen content (by atomic count) was reduced from $58 \%$ to $6 \%$ in steel-steel tests, and $17 \%$ to $1 \%$ in titanium-titanium tests, in the steady state (1000-10000 cycle) debris samples. This reduction has therefore proven sufficient to study the effects of oxide debris on wear rate. Furthermore the debris capture and analysis techniques have allowed for the collection of data on particle size and composition in various cycle ranges throughout the experiment. 


\subsection{Effects of oxygen availability on wear rates}

Considering figure 8, it is clear that the availability of oxygen in the contact has a substantial effect on wear rates, although this effect is not consistent between metals. Oxygen availability in steel-steel contacts caused a marked drop in wear rates, whilst in both titanium-steel and titanium-titanium tests, the wear rates were higher in air than argon. Polynomial best fits were found for the wear volume vs cycle number data and differentiated to give wear rates, plotted in figure 9. Titanium-titanium and titanium-steel contacts wear faster in air than argon, by a consistent factor of around 40, by volume. Steel-steel contacts however, produce a non-linear relationship between cycle number and wear rate. Wear rates in steel-steel tests were higher in air than argon (initially by a factor of 2), up until around the 60th cycle as shown in figure 9, after which argon tests exhibited higher wear rates. In the steady state, these tests exhibited a wear rate that is approximately 4 times higher in argon than air, indicating that iron oxides do provide a protective effect under these conditions as observed in the literature. This is consistent with the findings of [12] in that it suggests that iron oxides are protective in bulk once a significant third body presence can be maintained: however it may act as an abrasive before this point. The complexity and disparity of the effects of debris presence on wear rates indicate clearly why simple wear models do not make accurate predictions for fretting contacts, which are more able to retain this debris.

\subsection{Glaze layer (third body formation)}

These results show that in a developed contact, iron oxide presence reduces wear rates whilst titanium oxides increase them. Whilst hardness is the material property most often linked to wear rates in classical models (Archard), the effects of these debris types are unlikely due only to particle hardness, as the two most prevalent oxides for these metals $\left(\mathrm{TiO}_{2}\right.$ and $\mathrm{Fe}_{3} \mathrm{O}_{4}$ ) have very similar hardness [47] [48]. Particle size is another debris parameter linked to wear rates. According to Stott et al [27], oxide particles in the size range 10-50nm are required for the formation of a stable glaze layer, a phenomenon to which the mild wear in steels is attributed. Figures 11 and 12 show the size distributions of the two types of debris in the steel-steel tests conducted here. The iron oxide debris samples for the steady state of the steel-steel-air tests, contained only particles of this 10-50 nm size range or smaller and the EDS data for this sample given in figure 14, shows that the ratio of oxygen to iron in the sample is consistent with a $100 \%$ oxide $\left(\mathrm{Fe}_{3} \mathrm{O}_{4}\right)$ sample, making it an ideal state for glaze layer formation according to those findings. Outside of the steel-steel-air steady state debris, these size and composition conditions were not observed. The mean size of the debris recovered from any other test, was 10-100 times the size required for glaze layer formation according to Stott et al. Also, the oxygen content of these samples indicates that they could not be $100 \%$ oxide. The highest steady state oxygen content other than steel-steel-air was titanium-steel-air, which was $44 \%$ oxide. A glaze layer is unable to form under these conditions. 


\subsection{Dependence of wear rates on pressure}

A transition in wear rate is observed for steel-steel tests in both air and argon within the first 2000 cycles. This transition is not seen in other tests; they are linear. Linearity of wear rate with respect to cycle number with a crossed cylinder geometry indicates independence of the active wear mechanisms to changes in contact area, thus independence to changes in pressure, debris ejection, oxygen availability (as proposed by warmuch et al[13]), as well as independence to cycle or time related factors such as the formation of protective third bodies. Glaze layer formation might explain the bi-linear worn volume graphs in the steelsteel air tests, however a non-linear wear rate is also observed in the steel-steel-argon tests, in which a protective glaze layer could not formed due to the lack of oxide debris. This suggests that steel-steel-argon contacts wear by mechanisms sensitive to contact area, since a third body is not produced and the transition not as sharp. Considering pressure change as the factor driving this transition, Figure 10 shows the ratio of wear rate to pressure, vs cycle number for all tests. The steel-steel experiments (in air and argon) both show strong linearity with pressure in the steady state, but not before cycle 3000. Titanium tests, however, do not exhibit this linear relationship at any point. This shows how Archardbased models could make useful predictions in some contacts, as shown by Mccoll et al [7]. However it is clear that they are not suitable for modelling of all wear mechanisms. Since there is no consistent correlation with pressure, other factors such as debris ejection rate, may dominate in mechanisms active in the running in period.

\subsection{Dependance of wear rates on sample hardness}

The wear rates of titanium-titanium tests and titanium-steel tests, shown in figure 8, are indistinguishable from one another in both argon (very low wear rate) and air (high wear rate). This is contradictory to common results in literature and classical models (Archard), in which the hardness of the softer material is linked to wear rates [5]. The Vickers hardness of the titanium and steel were 344 and 293 respectively. Whilst the wear rate is identical between the two experiments for almost the entire duration of the experiment, the distribution of this worn volume between the moving and static samples is not. The average ratio of worn volume (moving: static) in the titanium-titanium tests was 2 , whilst in titanium-steel tests, this was 2.6, ie, 2.6 times the wear on the moving titanium sample as on the static steel sample. Experiments performed by Lemm et al [11], showed that in fretting wear, softer materials are more able to adhere with protective debris layers than hard materials causing more wear in the harder body. This agrees with the result presented here, in that the harder body wears faster: however, for a mechanism different to that proposed by Lemm et al, as the oxide debris in this contact is clearly detrimental rather than protective. It is suggested that this idea can be extended to include abrasive debris as well as protective debris, ie, hard, abrasive debris will also preferentially adhere to the softer body. Since abrasive wear by debris particles requires relative motion with a surface, if the softer surface is more able to retain particles then it follows that it would receive less abrasive damage. 


\subsection{The influence of debris on model validity}

There is a significant difference in the volume of metal removed by wear between the vertical and horizontal samples, see section 4.5. This shows clearly why pointwise models (those which assume that the wear rate at a given point can be fully determined by values such as stress, calculated at that point), can not work in fretting. Since the magnitude of tractions at a point in a wearing surface must be equal to those at the corresponding point in the counterbody, these models predict that for same material contacts, both components must wear at the same rate. This assumption might be valid in full sliding wear, where the amount of debris in a contact at any time is small, so the majority of the load is transferred directly through asperity contact. However, the additional presence of debris in fretting contacts allows for significant differences in the distribution of stress between contacting bodies, when load is carried primarily through debris particles.

Simple analytic models of single wear mechanisms, such as the Archard law, fail in fretting as the mechanisms responsible for wear depend upon debris (rather than asperity) interactions. The Archard law predicts that wear rate is proportional to load and a wear coefficient, and inversely proportional to hardness. The results presented here show that in fretting wear, none of these predictions stand. Load and hardness were constant for all tests but worn volume is still non-linear with cycle number for all steel-steel tests. Furthermore, the changes in wear rate corresponding to oxygen availability show that any empirically determined "wear coefficient" has no predictive capability outside of the wear mechanism from which it was determined.

\subsection{Structure and effects of titanium debris particles}

The largest disparities in wear rates were observed in titanium-titanium / titanium-steel, between air and argon tests. Clearly the availability of oxygen in the contact results in a large increase in wear rate. The cause of this additional damage is therefore, a consequence of surface oxidation, debris oxidation, or both. The size of the debris particles (micron scale) exhibited in figure 13 is large relative to the depth of surface oxidation in titanium. This indicates that particles cannot be pieces of detached surface oxide as is hypothesised for steel-steel oxide debris. The debris particles from this test must therefore be surface oxidised titanium particles. This is in agreement with the EDS results in figure 14. The particles observed in EDS were mostly titanium with a small quantity of oxygen (37\% maximum, with a $17 \%$ mean) and no pure oxide particles were found.

\subsection{Friction, dissipated energy, and wear rates}

Wear research often conflates wear and friction, treating a relationship between these two quantities as an axiom. Dissipated energy, calculated by methods described by Fouvry et al [49], is a useful metric of friction. The energy dissipated in the experiments performed in this study are given in figure 17. This graph shows that in all tests, the energy dissipation rate was constant for the entire cycle range. The difference in this rate is negligible between the majority of the experiments, with the exception of the steel-steel-argon test, which is up to twice that of the others. This result conflicts with the idea first presented by Fouvry et al, that wear rate is proportional to the rate of energy dissipation, since the data presented 
herein demonstrate no such linear relationship between wear rate and dissipated energy. If this were the case, non-linearity in wear rates exhibited in figure 8 would also be evident in the energy dissipation graphs. In explanation of this, it is suggested that in fretting wear, the interaction of debris particles in a contact would allow for dissipation of energy without damage to the first bodies.

\section{Conclusions}

A highly repeatable, novel experiment comprising several (typically separate modules) has been developed to study fretting wear. This allows the measurement of debris particle size distribution and composition, with time stamped data, with control of oxygen availability in the contact. In the argon atmosphere, the wear rate of titanium was reduced to 2.5 $\%$ of its control value. The wear rate of steel increased to $400 \%$ of its control value for the same change in oxygen availability.

The effect of oxygen availability on wear is strongly material dependent. The empirical evidence presented indicates that the cause for this material dependency is the change in the resultant debris particle size, not particle hardness as is often suggested. The size of the particles, not their hardness, is a more suitable predictor of wear rate. Evidence suggests that this a consequence of the inability of relatively large particles to form a glaze layer, in agreement with the glaze layer / sintering literature. In experiments with both debris sizes present, the mechanisms resulting from large particles were dominant, indicating that even when small $(<50 \mathrm{~nm})$ particles are present, glaze layer formation is disrupted by larger particles.

Literature on the numerical modelling of fretting wear exhibits an increased focus on debris modelling. The results of this paper demonstrate the importance of sintering mechanisms and of correctly modelling the size of debris particles in a fretting contact. Also provided here is an experimental method for determining the size and composition of debris particles for the validation of such models, which will be required to develop their predictive capability and to extend their use to different materials pairs and contact conditions.

\section{Acknowledgements}

The authors are grateful to Rolls-Royce plc for providing the financial support for this project and for giving permission to publish this work. This work is part of a Collaborative R\&T Project 'SAGE 3 WP4 Nonlinear Systems' supported by the CleanSky Joint Undertaking and carried out by Rolls-Royce plc and the University of Exeter.

\section{References}

[1] R. B. Waterhouse, Fretting fatigue. Elsevier Science \& Technology, 1981.

[2] Y. Berthier, L. Vincent, and M. Godet, "Fretting fatigue and fretting wear," Tribology international, vol. 22, no. 4, pp. 235-242, 1989. 
[3] O. Vingsbo and S. Söderberg, "On fretting maps," Wear, vol. 126, no. 2, pp. 131-147, 1988.

[4] Z.-b. Cai, M.-h. Zhu, and Z.-r. Zhou, "An experimental study torsional fretting behaviors of lz50 steel," Tribology International, vol. 43, no. 1, pp. 361-369, 2010.

[5] J. Archard, "Contact and rubbing of flat surfaces," Journal of applied physics, vol. 24, no. 8, pp. 981988, 1953.

[6] J. J. Madge, Numerical modelling of the effect of fretting wear on fretting fatigue. PhD thesis, University of Nottingham, 2009.

[7] I. McColl, J. Ding, and S. Leen, "Finite element simulation and experimental validation of fretting wear," Wear, vol. 256, no. 11, pp. 1114-1127, 2004.

[8] B. Roylance, T. Sperring, and T. Barraclough, "Bench test determinations of wear modes to classify morphological attributes of wear debris," in Bench Testing of Industrial Fluid Lubrication and Wear Properties Used in Machinery Applications, ASTM International, 2001.

[9] H. Costa, M. O. Junior, and J. de Mello, "Effect of debris size on the reciprocating sliding wear of aluminium," Wear, vol. 376, pp. 1399-1410, 2017.

[10] I. Hutchings and P. Shipway, Tribology: friction and wear of engineering materials. ButterworthHeinemann, 2017.

[11] J. Lemm, A. Warmuth, S. Pearson, and P. Shipway, "The influence of surface hardness on the fretting wear of steel pairs - its role in debris retention in the contact," Tribology International, vol. 81, pp. 258$266,2015$.

[12] A. Iwabuchi, "The role of oxide particles in the fretting wear of mild steel," Wear, vol. 151, no. 2, pp. 301-311, 1991.

[13] A. Warmuth, S. Pearson, P. Shipway, and W. Sun, "The effect of contact geometry on fretting wear rates and mechanisms for a high strengthsteel," Wear, vol. 301, no. 1, pp. 491-500, 2013.

[14] R. Antoniou and C. Subramanian, "Wear mechanism map for aluminium alloys," Scripta metallurgica, vol. 22, no. 6, pp. 809-814, 1988.

[15] M. Farias, R. Souza, A. Sinatora, and D. Tanaka, "The influence of applied load, sliding velocity and martensitic transformation on the unlubricated sliding wear of austenitic stainless steels," Wear, vol. 263, no. 1, pp. 773-781, 2007.

[16] X. Li and K. Tandon, "Microstructural characterization of mechanically mixed layer and wear debris in sliding wear of an al alloy and an al based composite," Wear, vol. 245, no. 1, pp. 148-161, 2000.

[17] Z. Peng and T. Kirk, "Computer image analysis of wear particles in three-dimensions for machine condition monitoring," Wear, vol. 223, no. 1, pp. 157-166, 1998.

[18] Y. Peng, T. Wu, S. Wang, and Z. Peng, "Wear state identification using dynamic features of wear debris for on-line purpose," Wear, vol. 376, pp. 1885-1891, 2017.

[19] M. Kumar, P. Shankar Mukherjee, and N. Mohan Misra, "Advancement and current status of wear debris analysis for machine condition monitoring: a review," Industrial Lubrication and Tribology, vol. 65, no. 1, pp. 3-11, 2013.

[20] T. Wu, H. Wu, Y. Du, and Z. Peng, "Progress and trend of sensor technology for on-line oil monitoring," Science China Technological Sciences, vol. 56, no. 12, pp. 2914-2926, 2013.

[21] V. Done, D. Kesavan, T. Chaise, D. Nelias, et al., "Semi analytical fretting wear simulation including wear debris," Tribology International, vol. 109, pp. 1-9, 2017.

[22] N. Fillot, I. Iordanoff, and Y. Berthier, "Modelling third body flows with a discrete element method-a tool for understanding wear with adhesive particles," Tribology International, vol. 40, no. 6, pp. 973-981, 2007.

[23] B. D. Leonard, A. Ghosh, F. Sadeghi, S. Shinde, and M. Mittelbach, "Third body modeling in fretting using the combined finite-discrete element method," International Journal of Solids and Structures, vol. 51, no. 6, pp. 1375-1389, 2014.

[24] Y. Peng, T. Wu, S. Wang, and Z. Peng, "Oxidation wear monitoring based on the color extraction of on-line wear debris," Wear, vol. 332, pp. 1151-1157, 2015.

[25] N. Myshkin, H. Kong, A. Y. Grigoriev, and E.-S. Yoon, "The use of color in wear debris analysis," Wear, vol. 251, no. 1, pp. 1218-1226, 2001. 
[26] F. Stott, "High-temperature sliding wear of metals," Tribology International, vol. 35, no. 8, pp. 489-495, 2002.

[27] F. Stott and G. Wood, "The influence of oxides on the friction and wear of alloys," Tribology International, vol. 11, no. 4, pp. 211-218, 1978.

[28] I. Inman, Compacted oxide layer formation under conditions of limited debris retention at the wear interface during high temperature sliding wear of superalloys. Universal-Publishers, 2006.

[29] Y.-H. Zhou, M. Harmelin, and J. Bigot, "Sintering behaviour of ultra-fine fe, ni and fe-25wt\% ni powders," Scripta metallurgica, vol. 23, no. 8, pp. 1391-1396, 1989.

[30] A. Begelinger and A. De Gee, "Sliding characteristics of silver against iron as influenced by oxygen concentration," ASLE TRANSACTIONS, vol. 10, no. 2, pp. 124-133, 1967.

[31] K. Miyoshi, "Considerations in vacuum tribology (adhesion, friction, wear, and solid lubrication in vacuum)," 1999.

[32] J. Jellison, R. Predmore, and C. Staugaitis, "Sliding friction of copper alloys in vacuum," ASLE TRANSACTIONS, vol. 12, no. 2, pp. 171-182, 1969.

[33] T. Akagak and D. Rigney, "Sliding friction and wear of metals in vacuum," Wear, vol. 149, no. 1, pp. 353-374, 1991.

[34] STEELEXPRESS, "EN24T Steel Properties." http://www.steelexpress.co.uk/engineeringsteel/EN24Tproperties.html. Online; accessed 12 October 2017.

[35] NeoNickel, "Ti 6Al-4V (Grade 5)." https://www.neonickel.com/alloys/titanium-alloys/ti-6al-4v/ . Online; accessed 12 October 2017.

[36] M. Kalin and J. Vižintin, "Comparison of different theoretical models for flash temperature calculation under fretting conditions," Tribology International, vol. 34, no. 12, pp. 831-839, 2001.

[37] MatWeb, LLC., "Titanium Ti-6Al-4V (Grade 5), Annealed." http://asm.matweb.com/search/SpecificMaterial.asp?ba . Online; accessed 12 October 2017.

[38] S. Pearson, P. Shipway, J. Abere, and R. Hewitt, "The effect of temperature on wear and friction of a high strength steel in fretting," Wear, vol. 303, no. 1, pp. 622-631, 2013.

[39] C. Bantz, O. Koshkina, T. Lang, H.-J. Galla, C. J. Kirkpatrick, R. H. Stauber, and M. Maskos, "The surface properties of nanoparticles determine the agglomeration state and the size of the particles under physiological conditions," Beilstein journal of nanotechnology, vol. 5, p. 1774, 2014.

[40] S. Roessler, R. Zimmermann, D. Scharnweber, C. Werner, and H. Worch, "Characterization of oxide layers on ti6al4v and titanium by streaming potential and streaming current measurements," Colloids and Surfaces B: Biointerfaces, vol. 26, no. 4, pp. 387-395, 2002.

[41] C. A. Schneider, W. S. Rasband, and K. W. Eliceiri, "Nih image to imagej: 25 years of image analysis," Nature methods, vol. 9, no. 7, pp. 671-675, 2012.

[42] ImageJ, "Automatic Particle counting." https://imagej.net/Particle_Analysis. Online; accessed 8th January 2018.

[43] S. Fouvry, P. Kapsa, H. Zahouani, and L. Vincent, "Wear analysis in fretting of hard coatings through a dissipated energy concept," Wear, vol. 203, pp. 393-403, 1997.

[44] A. M. Tobi, P. Shipway, and S. Leen, "Gross slip fretting wear performance of a layered thin w-dlc coating: Damage mechanisms and life modelling," Wear, vol. 271, no. 9-10, pp. 1572-1584, 2011.

[45] R. Bosman and D. J. Schipper, "Transition from mild to severe wear including running in effects," Wear, vol. 270, no. 7-8, pp. 472-478, 2011.

[46] K. Hiratsuka and K. Muramoto, "Role of wear particles in severe-mild wear transition," Wear, vol. 259, no. 1-6, pp. 467-476, 2005.

[47] AZO Materials, "Titanium Dioxide - Titania ( TiO2)." https://www.azom.com/properties.aspx?ArticleID=1179. Online; accessed 23rd March 2018.

[48] Reade, "Black Iron Oxide / Magnetite (Fe3O4) Powder." https://www.reade.com/products/black-ironoxide-magnetite-fe3o4-powder. Online; accessed 23rd March 2018.

[49] S. Fouvry, P. Kapsa, and L. Vincent, "Quantification of fretting damage," Wear, vol. 200, no. 1-2, pp. 186-205, 1996. 